\title{
Pseudomonas aeruginosa genomic structure and diversity
}

\author{
Jens Klockgether*, Nina Cramer, Lutz Wiehlmann, Colin F. Davenport and Burkhard Tümmler
}

Klinik für Pädiatrische Pneumologie, Allergologie und Neonatologie, Klinische Forschergruppe, Hannover, Germany

Edited by:

Dara Frank, Medical College of

Wisconsin, USA

Reviewed by:

Kalai Mathee, Florida International

University, USA

Alan Hauser, Northwestern

University, USA

Craig Winstanley, University of

Liverpool, UK

${ }^{*}$ Correspondence:

Jens Klockgether, Klinik für

Pädiatrische Pneumologie,

Allergologie und Neonatologie,

Klinische Forschergruppe, OE 6710,

Medizinische Hochschule Hannover,

Carl-Neuberg-Str. 1, D-30625

Hannover, Germany.

e-mail: klockgether.jens@

mh-hannover.de
The Pseudomonas aeruginosa genome ( $\mathrm{G}+\mathrm{C}$ content $65-67 \%$, size 5.5-7 Mbp) is made up of a single circular chromosome and a variable number of plasmids. Sequencing of complete genomes or blocks of the accessory genome has revealed that the genome encodes a large repertoire of transporters, transcriptional regulators, and two-component regulatory systems which reflects its metabolic diversity to utilize a broad range of nutrients. The conserved core component of the genome is largely collinear among $P$. aeruginosa strains and exhibits an interclonal sequence diversity of $0.5-0.7 \%$. Only a few loci of the core genome are subject to diversifying selection. Genome diversity is mainly caused by accessory DNA elements located in 79 regions of genome plasticity that are scattered around the genome and show an anomalous usage of mono- to tetradecanucleotides. Genomic islands of the pKLC102/PAGI-2 family that integrate into tRNA ${ }^{\text {Lys }}$ or tRNA ${ }^{\text {Gly }}$ genes represent hotspots of inter- and intraclonal genomic diversity. The individual islands differ in their repertoire of metabolic genes that make a large contribution to the pangenome. In order to unravel intraclonal diversity of $P$. aeruginosa, the genomes of two members of the PA14 clonal complex from diverse habitats and geographic origin were compared. The genome sequences differed by less than $0.01 \%$ from each other. One hundred ninety-eight of the 231 single nucleotide substitutions (SNPs) were non-randomly distributed in the genome. Non-synonymous SNPs were mainly found in an integrated Pf1-like phage and in genes involved in transcriptional regulation, membrane and extracellular constituents, transport, and secretion. In summary, P. aeruginosa is endowed with a highly conserved core genome of low sequence diversity and a highly variable accessory genome that communicates with other pseudomonads and genera via horizontal gene transfer.

Keywords: Pseudomonas aeruginosa, genome, genomic island, core genome, accessory genome, clonal complex, oligonucleotide signature

\section{INTRODUCTION}

The genetic repertoire of Pseudomonas aeruginosa reflects the lifestyle of this ubiquitous bacterial species. P. aeruginosa strains are found in various environmental habitats as well as in animal and human hosts, where they can act as opportunistic pathogens. The colonization of this broad spectrum of habitats goes along with the ability to exploit many different nutrition sources and a high potential for adaptation to new (or changing) environmental conditions (Ramos, 2004).

The metabolic versatility is provided by genes encoding not only the enzymes participating in metabolic pathways, but also by a very high number of transcriptional regulators and twocomponent regulatory systems. More than 500 regulatory genes were identified in the genome of strain PAO1 (Stover et al., 2000). The genomes of $P$. aeruginosa strains are larger than those of most sequenced bacteria. Within the species, the genome size varies between 5.5 and $7 \mathrm{Mbp}$ (Schmidt et al., 1996; Lee et al., 2006).

The divergence in genome size is caused by the so-called accessory genome. The major part of the genome, the core genome, is found in all $P$. aeruginosa strains with the respective DNA generally collinearly arranged (Römling et al., 1995). The core genome, with few exceptions of loci subject to diversifying selection, is highly conserved among clonal complexes and shows sequence diversities of $0.5-0.7 \%$ (Spencer et al., 2003; Lee et al., 2006; Cramer et al., 2011). The accessory genome consists of extrachromosomal elements like plasmids and of blocks of DNA inserted into the chromosome at various loci. The elements of the accessory genome can be present in subgroups of the $P$. aeruginosa population but may also occur only in single strains (Klockgether et al., 2007; Wiehlmann et al., 2007). The individual composition of the accessory genome accounts for most intra- and interclonal genome diversity in $P$. aeruginosa. The elements of the accessory genome were apparently acquired by horizontal gene transfer from different sources including other species or genera. Upon integration into the host chromosome they appear as "foreign" blocks in the core genome. Therefore, a $P$. aeruginosa chromosome is often described as a mosaic structure of conserved core genome frequently interrupted by the inserted parts of the accessory genome.

The individual mosaics also show remarkable plasticity. Ongoing acquisition of new foreign DNA as well as larger or smaller deletion events, mutations of single nucleotides and even chromosomal inversions (Römling et al., 1997; Ernst et al., 2003; Kresse et al., 2003; Smith et al., 2006; Klockgether et al., 2010; Cramer et al., 2011) - all of them potentially affecting parts of the core and/or the accessory genome - continuously modify the genome, 
modulate the $P$. aeruginosa strain's phenotype and differentiate it from others.

Genome diversity of $P$. aeruginosa was initially analyzed by low-resolution physical mapping techniques (Schmidt et al., 1996; Römling et al., 1997). Thanks to progress in DNA sequencing technologies $P$. aeruginosa genomes can nowadays be compared by the base (Kung et al., 2010; Silby et al., 2011).

\section{GENOME SEOUENCES}

Pseudomonas aeruginosa is ubiquitous in aquatic habitats and colonizes animate surfaces of humans, animals and plants. Complete genome sequences, however, are so far only available for $P$. aeruginosa isolates from human infections (Table 1).

The first complete genome sequencing was performed for strain PAO1 (Stover et al., 2000), derived from an Australian wound isolate from the 1950s. The PAO1 strain has been and is still the major reference for genetic and functional studies on P. aeruginosa. The PAO1 genome consists of a 6.264-Mbp circular chromosome encoding 5,570 predicted protein coding sequences. Sequence and annotation are deposited at the National Center for Biotechnology Information (NCBI) genome database (Refseq. no. NC_002516) and in the Pseudomonas Genome Database (Winsor et al., 2009), which also documents ongoing annotation updates. Thanks to the recently developed deep cDNA sequencing more and more noncoding RNAs are currently being identified in bacterial genomes, and thus we can expect a large number of non-coding genes to be added to the annotation of $P$. aeruginosa genomes as has been executed for Helicobacter pylori and Pseudomonas putida (Sharma et al., 2010; Frank et al., 2011).

The second $P$. aeruginosa genome sequence was published for the ExoU-positive strain PA14 (NC_008463, Lee et al., 2006), a clinical isolate displaying higher virulence than PAO1. Fifty-four PAO1 regions of at least one open reading frames (ORFs) are absent in the PA14 genome, and 58 PA14 regions are absent in PAO1 including the PA14 pathogenicity islands PAPI-1 and PAPI-2 (He et al., 2004).

LESB58, a so-called "Liverpool epidemic strain," was found to be highly transmissible among CF-patients and displayed the potential to cause severe infections even in non-CF human hosts (Cheng et al., 1996; McCallum et al., 2002). The LESB58 genome (NC_011770) contains previously unknown accessory genome elements (Winstanley et al., 2009).

PA7 is a clinical isolate from Argentina with a notably unusual antimicrobial resistance pattern. Strain PA7 (NC_009656) shares only $93.5 \%$ nucleotide identity in the core genome with the other sequenced strains confirming the previous assignment of strain PA7 as a taxonomic outlier within the species P. aeruginosa (Roy et al., 2010).
Almost complete genome sequences are also available for strains 2192 (NZ_AAKW00000000), C3719 (NZ_AAKV00000000), PACS2 (NZ_AAQW00000000; Mathee et al., 2008), and 39016 (AEEX00000000; Stewart et al., 2011). Eight additional P. aeruginosa genome sequences are listed at NCBI as "In Progress" (last checked on February 23rd, 2011) and numerous P. aeruginosa projects are deposited in the European Nucleotide Archive (ENA) hosted by EMBL-EBI ${ }^{1}$. With decreasing costs and increasing speed of sequencing we can expect an avalanche of novel P. aeruginosa genome sequence data. Published examples are the comparative sequencing of PAO1 sublines of divergent metabolic and virulence phenotypes (Klockgether et al., 2010), the identification of de novo mutations conferring antimicrobial resistance (Moya et al., 2009), the analysis of genomic gradients of sequence diversity in a pool of clinical isolates (Dötsch et al., 2010), and the intraclonal microevolution in the cystic fibrosis lung (Cramer et al., 2011).

\section{THE ACCESSORY GENOME}

The accessory genome consists of DNA elements from within the range of a few hundred bases to more than $200 \mathrm{kbp}$. The minimum size of an accessory element was defined as a block of at least four contiguous ORFs that are not conserved in all $P$. aeruginosa (Mathee et al., 2008). Thirty-eight to 53 accessory elements were identified in the completely sequenced $P$. aeruginosa genomes (Table 2). The PAO1 genome only contains inserts of $14 \mathrm{kbp}$ or smaller (Mathee et al., 2008), whereas the LESB58 genome harbors five genomic islands and five inserted prophages of $14-111 \mathrm{kbp}$ in size (Winstanley et al., 2009). Table 3 lists the subset of genomic islands that were analyzed in detail in silico and/or in wet lab experiments.

Within the chromosomally integrated islands, very often phages, transposons, or IS-elements are found indicating that the majority of the accessory genome originates from mobile DNA elements which have been acquired and kept by the host strain. Many elements were irreversibly fixed by secondary mutation or deletions, but a few others have retained their mobility and can still leave the chromosomal insertion site and be transferred elsewhere, as shown for the elements PAPI-1 (Qiu et al., 2006) and pKLC102 (Klockgether et al., 2007). For a detailed description of the different types of accessory elements [integrative and conjugative elements (ICEs), prophages, transposons, etc.], the reader is referred to the recently published review by Kung et al. (2010).

The acquisition of the elements of the accessory genome from other taxa is not only evident from the gene contents with its overrepresentation of mobile DNA elements, but also from global

\footnotetext{
${ }^{1}$ http://www.ebi.ac.uk/ena/
}

Table 1| Features of sequenced $P$ aeruginosa strains.

\begin{tabular}{lllllllll}
\hline Strain & PAO1 & PA14 & PA7 & LESB58 & PACS2 & $\mathbf{2 1 9 2}$ & C3719 & $\mathbf{3 9 0 1 6}$ \\
\hline Source & Wound & Clinical & Clinical & CF-patient & Clinical & CF-patient & CF-patient & Keratitis \\
Genome size (Mbp) & 6.264 & 6.538 & 6.588 & 6.602 & 6.492 & 6.905 & 6.222 & 6.667 \\
GC-content (\%) & 66.6 & 66.3 & 66.5 & 66.5 & 66 & 66.2 & 66.5 & 66 \\
No. of protein coding ORFs & 5570 & 5892 & 6286 & 5925 & 5676 & 6191 & 5578
\end{tabular}


Table 2 | Regions of genome plasticity (RGP) in seven sequenced $P$. aeruginosa genomes.

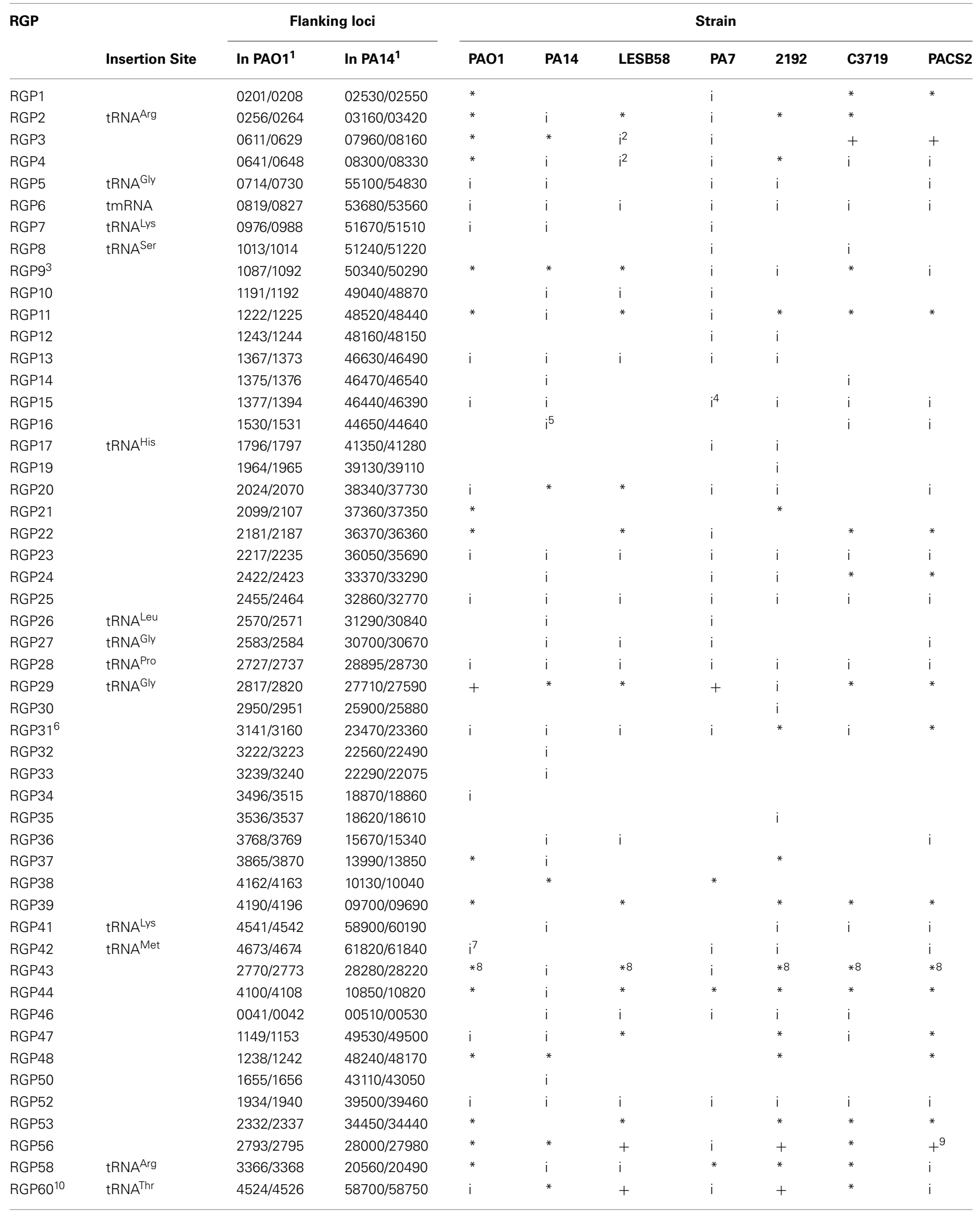


Table 2 | Continued

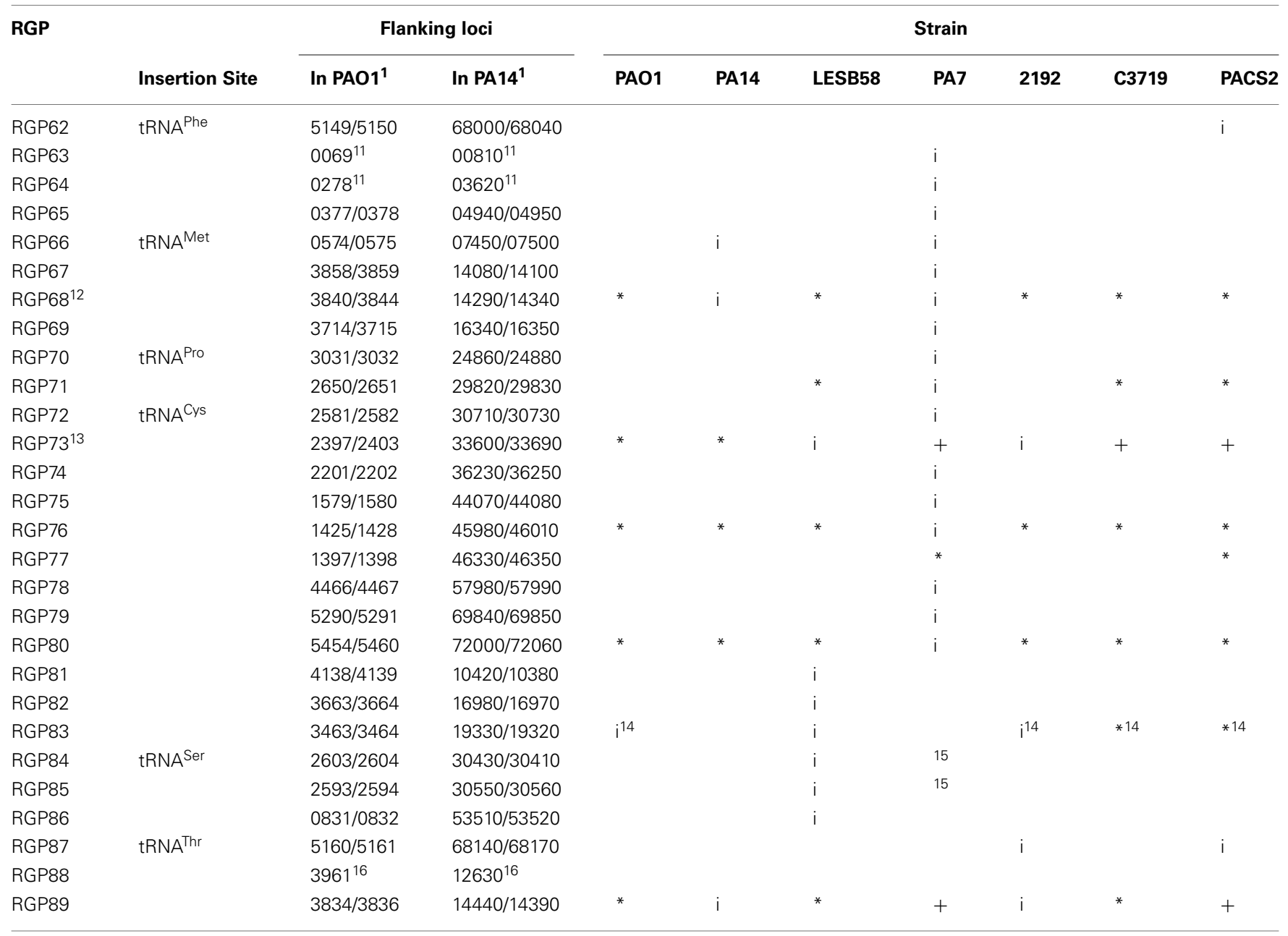

Differentiation of accessory elements in the RGPS: i, strain-specific accessory element; ${ }^{*}$ or + , identical accessory elements in two or more strains. RGPS $1-62$ were defined by Mathee et al. (2008) and RGPs 63-80 by Roy et al. (2010). The novel RGPs 81-89 were extracted from the sequences of genomic islands in strain LESB58 (RGP 81-86; Winstanley et al., 2009) and strain PSE9 (RGP 87-89; Battle et al., 2009).

'Insertions are designated by the numbers of the flanking loci in the PAO1 and PA14 genomes (e.g., 0201 is PA0201,02530 is PA14_02530).

${ }^{2}$ Insertion LESPP-1 between PA0612 and PA0648 homologs comprises RGP3 and RGP4.

${ }^{3}$ Region containing flagellin glycosylation genes (replacement island).

${ }^{4}$ Partial duplication of sequence of the core genome (between RGP27 and RGP28).

${ }^{5}$ No annotated ORF in this insertion.

${ }^{6}$ Region contains O-antigen gene cluster (replacement island).

${ }^{7}$ No insertion in PAO1 reference sequence but in variants PAO1-DSM and MPAO1 (Klockgether et al., 2010).

${ }^{8} /$ dentical sequence with discordant ORF annotation for the different strains.

${ }^{9} /$ dentical sequence with discordant annotation for PACS2 versus LESB58 and 2192.

${ }^{10}$ Region contains pilA gene (replacement island).

"Homologous ORF in PA7 disrupted by the insertion.

${ }^{12}$ Insertion contains exoS gene in PAO1, LESB58, 2192, C3719, and PACS2.

${ }^{13}$ Region contains pyoverdine synthesis gene cluster (replacement island).

${ }^{14}<1 \mathrm{~kb}$ insertion in PAO1, 2192, C3719, and PACS2 with no predicted ORF.

${ }^{15}$ Insertion in PA7 comprises RGP84 and RGP85.

${ }^{16}$ Homologous ORF in strain PSE9 disrupted by PAGI-7.

parameters like the oligonucleotide signature. The segments of the core genome share the same oligonucleotide usage, whereas the constituents of the accessory genome exhibit a divergent $\mathrm{G}+\mathrm{C}$ content and oligonucleotide usage (Reva and Tümmler, 2004,
2005). In the genome atlas of P. aeruginosa LESB58 (Figure 1), the regions with an anomalous tetranucleotide composition and an underrepresentation of common octa- to tetradecanucleotides coincide with the segments of the accessory genome. Figure 2 
Table 3 | Genomic islands in P. aeruginosa strains described in literature.

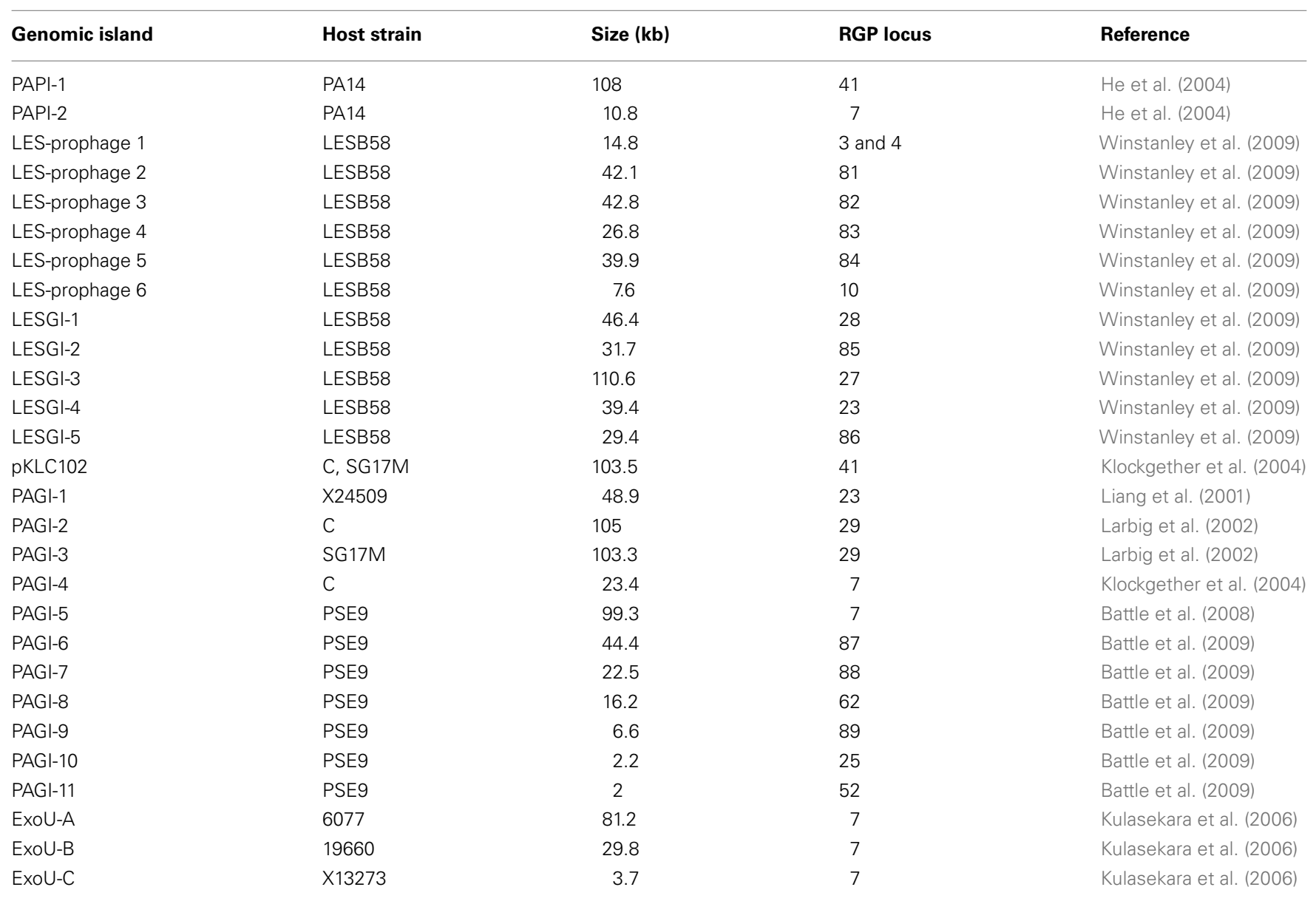

shows the genome distribution of the most abundant 8- to 14mers in P. aeruginosa LESB58 (Davenport et al., 2009). Regions that lack these strain- or taxon-specific words represent those parts of the accessory genome that is most foreign from the core.

\section{REGIONS OF GENOME PLASTICITY}

Elements of the accessory genome are located in all sections of the $P$. aeruginosa chromosome, not concentrated in some regions. Nevertheless, the uptake of accessory DNA apparently did not occur completely at random but at specific genomic loci that are prone to integration of special mobile elements.

A comprehensive comparison of the genomes of strains PAO1, PA14, 2192, C3719, and PACS2 (Mathee et al., 2008) led to the definition of so-called "regions of genome plasticity" (RGPs). Mathee and co-workers searched for segments of DNA not conserved in all five genomes and designated any region containing a block of four or more contiguous ORFs that is missing in at least one of the genomes as an RGP. For each of these RGPs they defined the DNA contained in the accessory blocks and the ORFs annotated within. Also the RGP flanking ORFs conserved in all five strains were listed, referred to as "anchors," which describe the genomic site used for the integration of the foreign DNA.

The approach by Mathee et al. (2008) appears reasonable to describe accessory and core genome of $P$. aeruginosa strains, although small insertions are ignored and deletions affecting the core genome in some, but not all, compared strains will misassign the respective segment to the accessory genome. A secondary check of the oligonucleotide usage will correct these false positives.

Mathee et al. (2008) initially defined 52 RGPs (no. 1-62 in Table 2). With the advent of the PA7 genome sequence, a further 18 elements were identified (RGPs 63-80; Roy et al., 2010).

Table 2 moreover lists the novel RGPs 81-89 that comprise yet unknown RGPs from strains LESB58 (Winstanley et al., 2009) and PSE9 (Battle et al., 2009).

On average each sequenced $P$. aeruginosa strain carries about 40 RGPs with insertions. The outlier was strain PA7 with 53 occupied RGPs. tRNA genes serve as integration sites for 20 RGPs. The $3^{\prime}$ end of tRNA genes and the subsequent nucleotides are known to serve as integration sites for ICEs and phage-like elements (Dobrindt et al., 2004). In the majority of RGPs, however, other target sequences had been utilized for the insertion corresponding with the diverse type and origin of the elements of the accessory genome of $P$. aeruginosa (Kung et al., 2010). Most target sequences are located in intergenic regions, but in three RGPs a single ORF was disrupted (RGPs 63, 64, and 88; Table 2). Interestingly, insertions in each of these three RGPs were only detected for a single strain so far, while in all other tested genomes the non-fragmented anchor-ORF was present. 


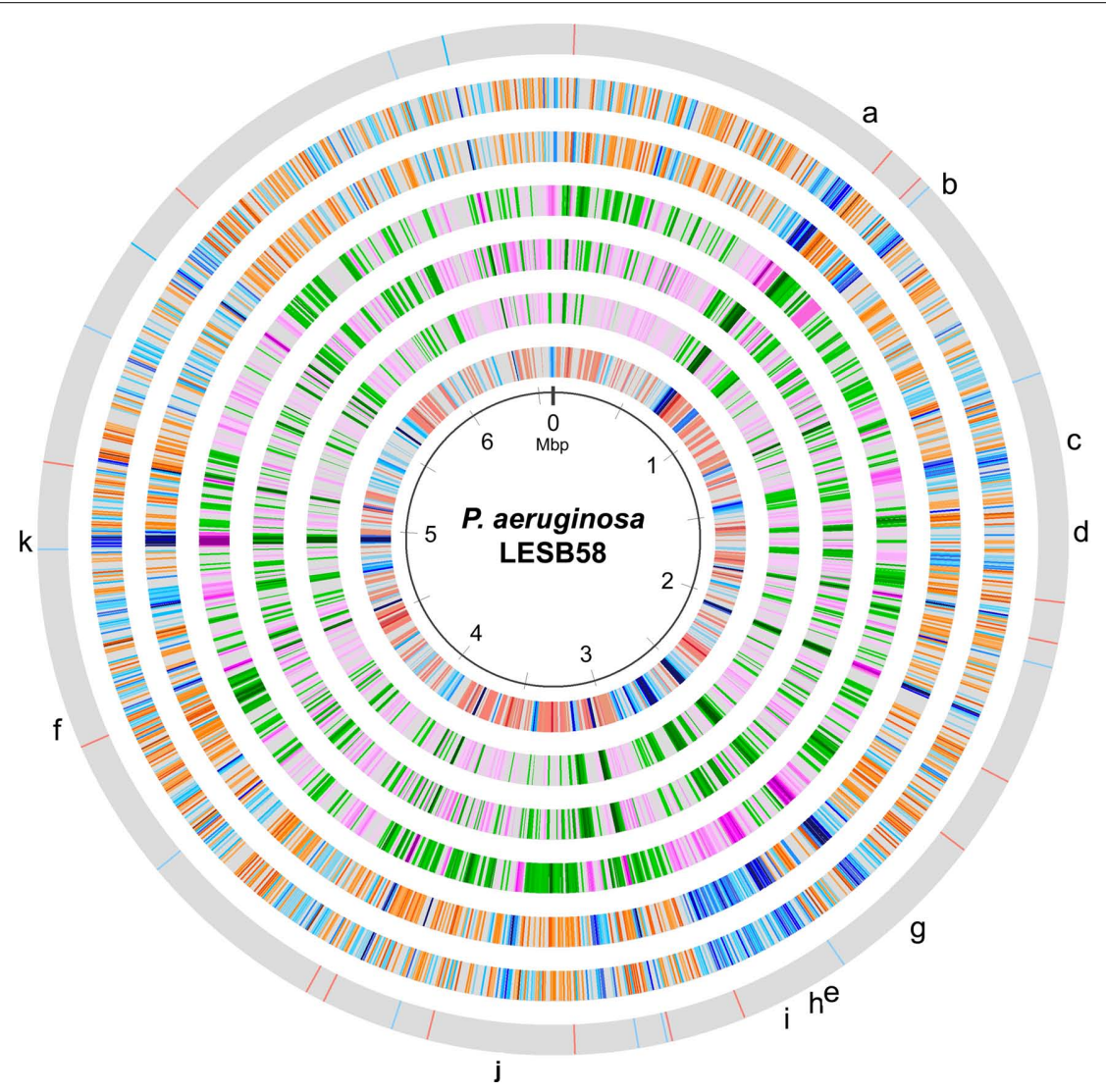

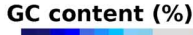

\begin{tabular}{lll}
\hline 58.0 & 66.2 & 74.5
\end{tabular}

Distance (\%)

$\begin{array}{lll}0.79 & 14.3 & 27.8\end{array}$

Pattern skew (\%)

$2.32 \quad 21.1 \quad 40.0$

Oligonucleotide variance

$\begin{array}{lll}0.14 & 0.81 & 1.48\end{array}$

\% 8-14mers at chiSq 3000

$\begin{array}{lll}5.40 & 19.4 & 33.4\end{array}$

\% 8-14mers at chiSq 7000

$\begin{array}{lll}0.0 & 3.28 & 6.88\end{array}$

4mer-8mer deviation (class)

$-10$ $+10$
FIGURE 1 | Genome atlas representations of $\mathbf{G}+\mathbf{C}$ content, tetranucleotide parameters and overrepresented 8- to 14 mers in $P$. aeruginosa LESB58 (Davenport et al., 2009). Increasing divergence from average (up to an extreme value at $\pm 3 \mathrm{SD}$ ) is indicated by progressively darker colors. $\mathrm{G}+\mathrm{C}$ content and the three tetranucleotide parameters are plotted on the innermost four rings. Distance (second innermost circle) is the distance between global and local sliding window tetranucleotide patterns, pattern skew (third innermost circle) is the distance between tetranucleotide rankings on direct and reverse strands, and oligonucleotide variance (fourth innermost circle) is the numerical variance of oligomers, where a lower value indicates tetramer usage is more highly restricted (for example in repeat regions). Rings 5 ( $\chi^{2}$ threshold 3000) and 6 ( $\chi^{2}$ threshold 7000) display the number of bases occupied by overrepresented 8 - to 14 mers in a certain region, with overlaps only counted once, as a percentage. The outermost ring shows the difference (in classes) between a tetranucleotide parameter, oligonucleotide variance, and the 8- to 14 mers in ring 5. Figures were created with JCircleGraph. Letters at the outermost ring indicate the regions of the six identified prophages (a-f) and five genomic islands (g-k; Winstanley et al., 2009).
Three regions show an unusual local genome structure. Strains LESB58 and PA7 each carry hybrids of two adjacent RGPs. Moreover, in strain LESB58 a 137-kbp segment of the core genome $3^{\prime}$ to RGB15 was transposed upstream by 83 genes ( $84.3 \mathrm{kbp}$; Figure 3 ). No repeats flanking the segment or mobility-related genes such as transposase- or integrase-coding genes were identified so that the underlying mechanism of the transposition remains elusive.

\section{THE pKLC102/PAGI-2 ICE FAMILY}

Among the genomic islands of the P. aeruginosa accessory genome, members of the pKLC102/PAGI-2 family are highly prevalent. They represent a special group of ICEs that can be described as semi-conserved elements, as they generally consist of individual DNA blocks and sets of genes common to all members (Klockgether et al., 2008; Kung et al., 2010). pKLC102/PAGI2 family islands have been detected in various bacterial species and genera, mainly in $\beta$ - and $\gamma$-proteobacteria. The fact that a set of genes is conserved among all family members indicates a common origin from an ancient ancestor (Mohd-Zain et al., 2004). This conserved gene set accounts for structural and mobility-related features and conjugal transfer. Individual genes within the islands can encode a broad spectrum of different functions, among them catabolic pathways as well as virulence effectors. Existence of free episomal forms and/or transfer to other strains, even across species barriers, have been monitored for several pKLC102/PAGI-2-like islands, thus confirming their role for (ongoing) evolution of bacterial genomes and, due to the different "cargo" provided by these elements to the host strains, for the genome diversification within bacterial species and emergence of subgroup- or strain-specific phenotypes. For a detailed summary of the role of the common "backbone" genes for integration, mobilization and transfer of pKLC102/PAGI-2like elements, the reader is referred to the recent review by Kung et al. (2010).

The role of pKLC102/PAGI-2-like islands within the $P$. aeruginosa accessory genome, and thus their contribution to genome 


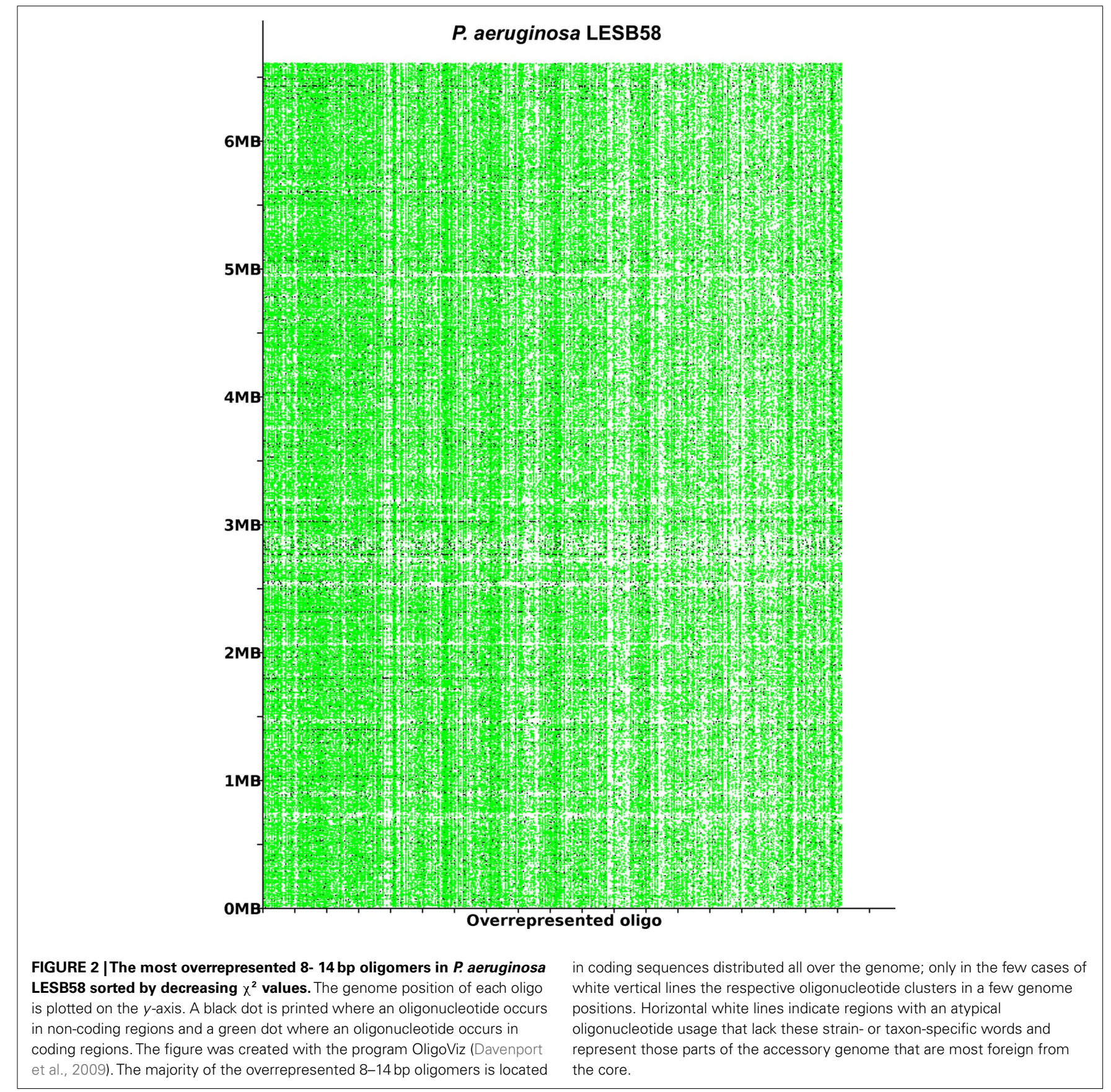

diversity, is illustrated by the abundance of many different islands of this family within the population. Hybridization results have indicated the presence of such islands in a majority of strains isolated from different habitats (Klockgether et al., 2007; Wiehlmann et al., 2007). Similarly, searching the available P. aeruginosa genome sequences for the typically conserved genes revealed their presence in all strains but PAO1.

Six of the islands listed in Table 3 are members of that family: pKLC102, PAPI-1, PAGI-5, PAGI-2, PAGI-3, and LESGI-3. All of them are between 99 and $110 \mathrm{kbp}$ in size. Clusters of typically conserved backbone genes were also detected in smaller islands like PAGI-4 or ExoU-A. As significant parts of the backbone, however, were missing, it was hypothesized that PAGI-4 and ExoU-A represent remaining fragments of formerly complete PAGI-2/pKLC102-like islands that underwent recombination and deletion events resulting in the loss of smaller (ExoU-A) or bigger parts (PAGI-4) of the original elements (Klockgether et al., 2004; Kulasekara et al., 2006).

The mentioned $P$. aeruginosa islands split up into two subtypes: PAGI-2-like islands (PAGI-2, PAGI-3, and LESGI-3) contain a phage P4-related integrase gene and are inserted at tRNA ${ }^{\text {Gly }}$ genes in RGPs 27 or 29. The well described $c l c$ element providing 


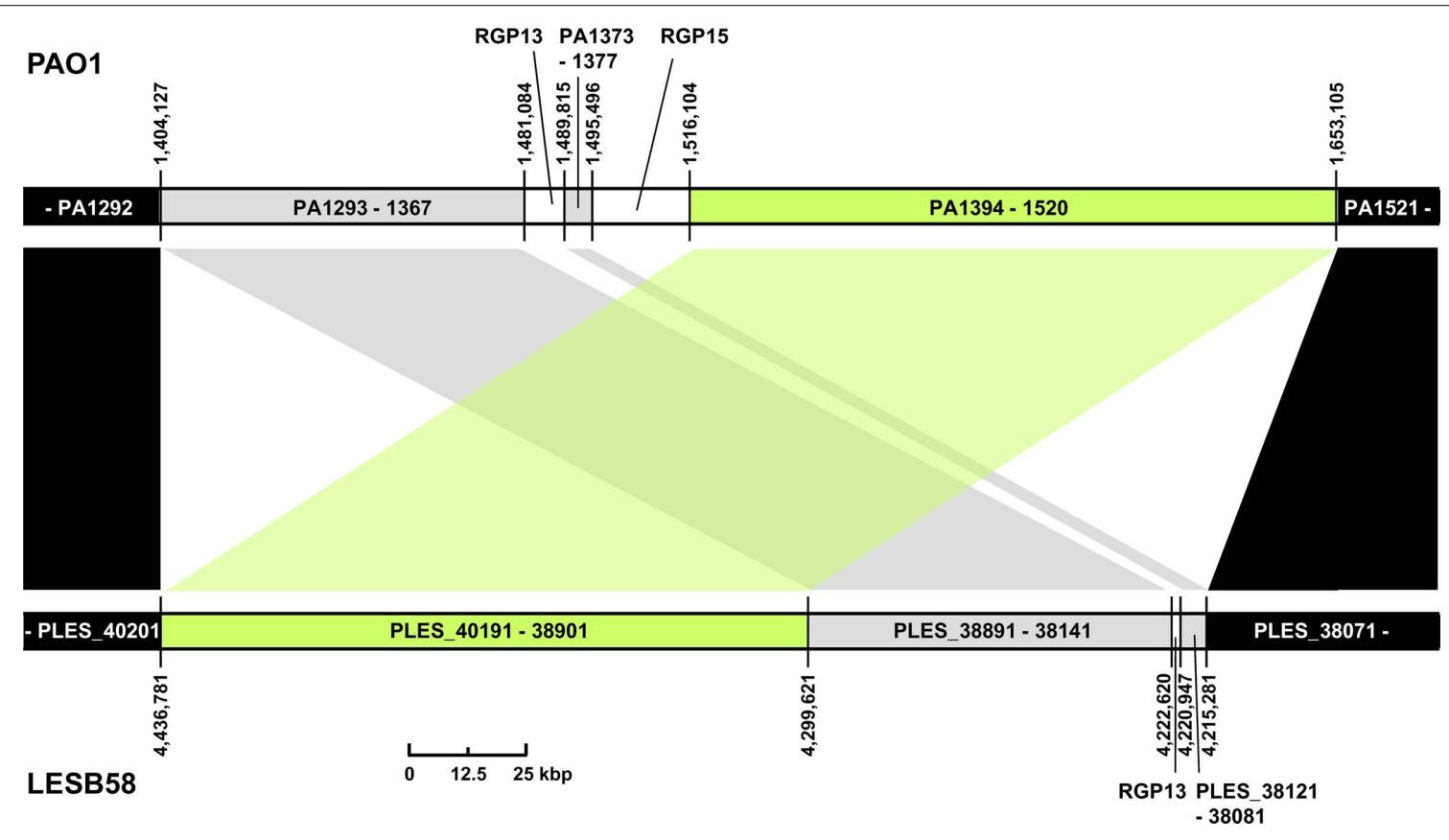

FIGURE 3 | Transposition of core genome DNA in LESB58. The genomic region with different core genome architecture is shown for strains PAO1 and LESB58. One hundred thirty-seven kbp of DNA (green) are located upstream of other core genome DNA blocks (gray) in LESB58 while occurring downstream of them in PAO1 (and other genomes). Surrounding core genome DNA arranged collinearly in both strains is shown in black, strain-specific insertions are represented by white areas. Genome coordinates of the borders of the core genome DNA blocks and numbers of the ORFs within are given for both strains. Accessory DNA blocks are described by the RGP number (see Table 2). features for metabolizing chlorinated aromatic compounds could be assigned to that subtype as well. Present in other Pseudomonas species as well as in Ralstonia and Burkholderia strains, transfer of clc to P. aeruginosa PAO1 by conjugation was shown in vitro (Gaillard et al., 2008). Upon transfer, genomic integration occurred at the usual tRNA ${ }^{\text {Gly }}$ genes in RGP27 or RGP29.

The pKLC102-subtype islands (pKLC102, PAPI-1, PAGI-5) are endowed with a XerC/XerD-like integrase gene, and the two copies of a tRNA ${ }^{\text {Lys }}$ gene in RGP7 and RGP41 can be used as insertion sites. Transfer of pKLC102-like elements from one RGP to the other has been demonstrated (Kiewitz et al., 2000; Qiu et al., 2006). The "fragmentary" pKLC102-like islands PAGI-4 and ExoU-A are also located in RGP7. The tRNA ${ }^{\text {Lys }}$ gene in RP7 is also the insertion site for islands carrying the virulence-associated exoU gene and its cognate chaperone $s p c U$ gene, ExoU-B, ExoU-C, and PAPI-2. Although DNA typical for pKLC102-like islands is scarce in these exoU-positive islands, the common insertion site and a few motifs within their sequence indicate a descent from a pKLC102-like element as hypothesized for ExoU-A (Kulasekara et al., 2006).

Kung et al. (2010) described the two subtypes as two families of $P$. aeruginosa ICEs. Due to the conserved function and synteny of the backbone genes, however, we prefer to consider them as members of one family with common ancestry (Klockgether et al., 2007,2008). The pKLC102/PAGI-2-like islands share 35 conserved orthologs with a variable degree of amino acid identity between 35 and $100 \%$.

Divergent evolution from the ancestor might have caused the early formation of the two pKLC102- and PAGI-2 subtypes that exhibit higher average identity values among the conserved backbone genes and each carry a subfamily-specific set of genes (Figure 4). Eleven genes were specific for the PAGI-2-subtype and 39 genes specific for the pKLC102- subtype including a cluster of conjugative type IV sex pilin genes (Klockgether et al., 2004; Carter et al., 2010). Thus, pKLC102-/PAGI-2-family islands appear as mosaic pieces in $P$. aeruginosa genomes while they are small mosaics themselves, composed of conserved backbone, subtype-specific, and individual cargo genes.

Due to their size, islands of this family can represent a major portion of the accessory genome. Strains with one or two large pKLC102/PAGI-2-family elements are common, but higher numbers per genome are possible. $P$. aeruginosa strain $\mathrm{C}$ harbors PAGI-2 and pKLC102, but two more sets of backbone ORFs have been identified in the chromosome indicating four related elements in total, with an overall DNA sequence length of more than $360 \mathrm{kbp}$ (own unpublished data). Of the seven genomes presented in Table 2, six contain large pKLC102/PAGI-2-family islands. Strains PA14, C3719, and PA7 each harbor one pKLC102-like island in RGP41 or, in case of PA7, in RGP7. LESB58 also contains one island, but of the PAGI-2 subtype (LESGI-3 in RGP27). Two islands each are located in the 2192- and the PACS2 genomes. Both strains also harbor a pKLC102-like insertion in RGP41 and a PAGI-2-related island, which is in RGP29 for strain 2192 and in RGP27 in PACS2.

The island in 2192 inserted at RGP29 is a nearly identical copy of PAGI-2 itself but is interestingly accompanied by another island of comparable size, the so-called Dit-island which is distinct from the 


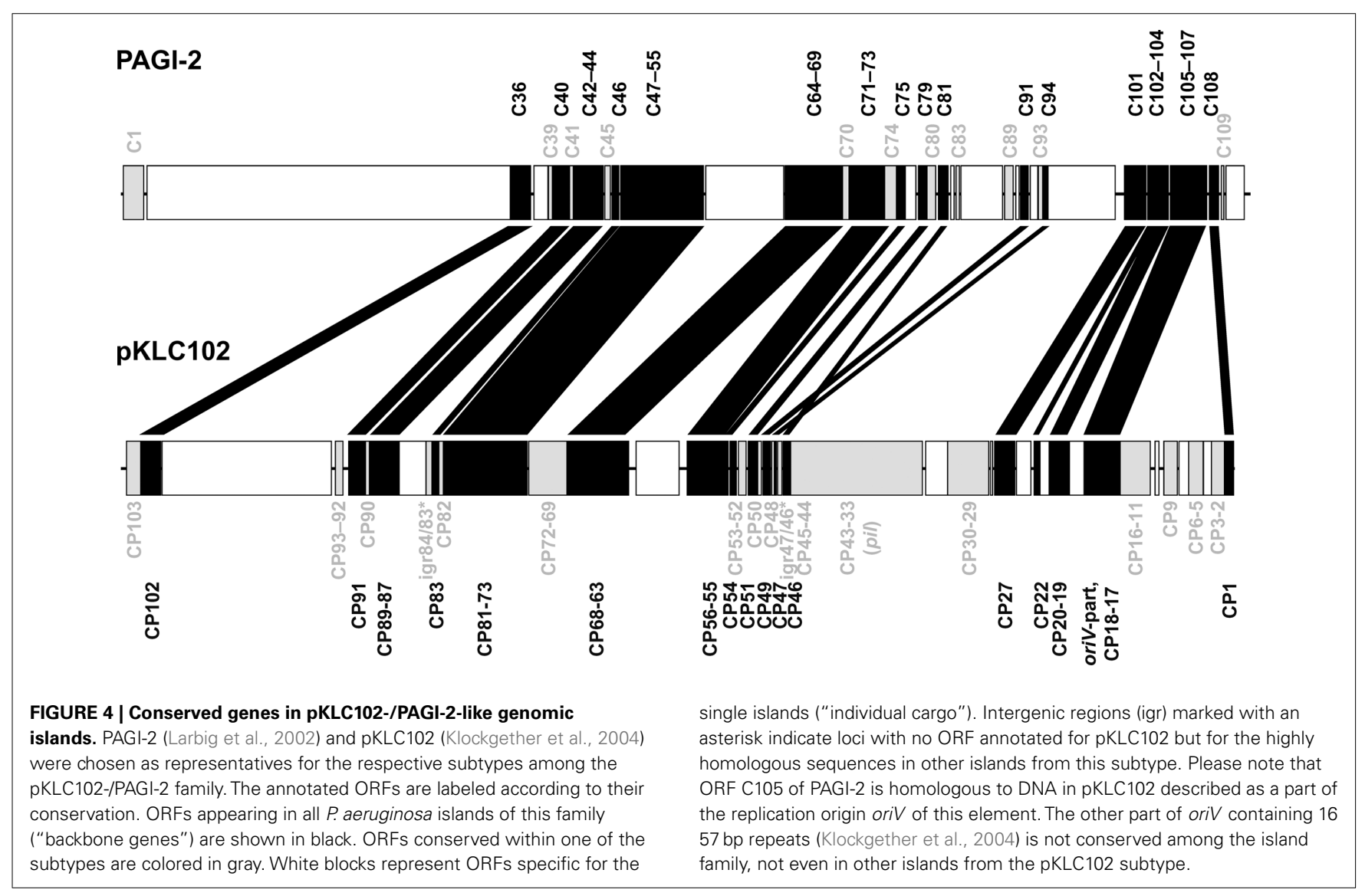

pKLC102/PAGI-2 family (Mathee et al., 2008). Thus an extremely large insertion of about $220 \mathrm{kbp}$ is present in RGP29, which probably resulted from successive acquisition of two elements using the same chromosomal integration site. The RGP41-insertion in strain PA7 also provides hints for a combination of genome islands. Next to the pKLC102-like island with all typically conserved genes a DNA block with a second copy of some of the backbone genes is located, resembling a fragment of a second pKLC102-like element linked to the first one (Klockgether et al., 2008; Roy et al., 2010).

\section{REPLACEMENT ISLANDS}

Table 2 also lists the loci in the core genome that are under diversifying selection, the so-called replacement islands: RGP9 (flagellin glycosylation genes), RGP31 (O-antigen biosynthesis genes), RGP60 (pilin gene), and RGP73 (pyoverdine gene cluster). The RGPs only encompass those genes that fulfill the definition of less than $70 \%$ nucleotide sequence identity between homologs and thus do not necessarily comprise the complete functional units (Mathee et al., 2008).

The types of each replacement island were identified by comparative sequencing of the respective gene clusters in $P$. aeruginosa strain collections. The 20 known O-antigen serotypes, for example, were assigned to 11 groups according to the criterion of more than $98 \%$ sequence identity in the major O-antigen biosynthesis gene cluster (Raymond et al., 2002).

RGP60, containing the pilA gene that encodes the major subunit for type IV attachment pili, was classified into groups I-V
(Kus et al., 2004). This “major pilin" region adjacent to a tRNA ${ }^{\text {Thr }}$ gene contains, besides pilA for all groups but group II, several $t f p$ genes that are involved in type IV pilus assembly and modification. More $t f p$ genes are located downstream in the "minor pilin" region. Each of the five major pilin regions is associated with a specific set of minor pilins, and unrelated strains with the same major pilin type have identical minor pilin genes (Giltner et al., 2011). The absolute linkage disequilibrium between major and minor pilin groups provides evidence that both regions were derived from one large island. Consistent with this interpretation more pilin assembly genes are located between the major and minor pilin groups. These genes, however, were not subject of diversifying selection. Moreover a tRNA gene cluster is located between the major and the minor pilin region that serves as a hotspot for integration of large pKLC102-like islands (RGP41). Thus, the genome distance between major and minor pilin gene clusters varies between $136 \mathrm{kbp}$ in strain PA14 and only $29 \mathrm{kbp}$ in PAO1.

The pyoverdine gene clusters I, II, and III encode the three pyoverdine types and their specific receptor. Intratype divergence driven by recombination, positive selection, and horizontal gene transfer have enhanced the diversity of this genomic region (Smith et al., 2005).

The two flagellins a and b differ in their primary amino acid sequence and their glycosylation from each other (Spangenberg et al., 1996). b-type flagellins are conserved in sequence and glycosylation (Verma et al., 2006). In contrast, six fliC single nucleotide substitutions (SNPs) haplotypes (Spangenberg et al., 1996) and 
differential glycosylation patterns lead to a large diversity of a-type flagellins (Arora et al., 2004). The variability of the a-type glycosylation gene cluster (RGP9) is high, even within the subtypes A1 and $\mathrm{A} 2$ that were defined by phylogenetic relatedness of amino acid sequences.

\section{THE $P$. AERUGINOSA PANGENOME}

The pangenome represents the complete gene pool of a bacterial species. Thus the description of a pangenome depends on the amount of sequence data available. For species with an extended accessory genome like $P$. aeruginosa, the addition of each new genome sequence will enlarge the overall pool of genes. The size of the core genome that is present in all strains will decrease concurrently.

To define the core genome and pangenome, the genomes are sequentially screened for orthologs by searching for reciprocal best BLAST hits. Genes that lack an ortholog in the already investigated gene pool are added to the pangenome.

We used the tool "Comparative Genome Search" provided by the Pseudomonas Genome Database ${ }^{2}$ to define the number of orthologs representing reciprocal best blast hits in the four fully sequenced genomes of PAO1, PA14, LESB58, and PA7 (BLASTP comparisons, $E$-value cutoff: $\left.1 \times 10^{-4}\right)$. The tool also allows the determination of individual genes per genome, so the number of genes contributing to the pangenome could be counted with paralogs excluded. The results are shown in Figure 5. Please note that the PAO1 gene pool is lower than the overall number of ORFs in this genome (5520 compared to 5570) due to this exclusion of paralogs. As expected the core genome decreases and the pangenome increases each by a few hundred genes with the addition of a new genome. Although the analysis of just four genomes is insufficient for the extrapolation of the gene pool of core genome and pangenome of $P$. aeruginosa, we can assume that the pangenome does not approach a saturation value. Each novel genome sequence will contribute a yet unknown gene set to the pangenome. The large genomic islands of the pKLC102/PAGI-2 family contribute a broad variety of cargo to the species. Each strain possesses an individual set of islands that is acquired by horizontal gene transfer preferentially from beta- and gamma-proteobacteria (Klockgether et al., 2008). In other words, $P$. aeruginosa has wide, but not unrestricted access to the gene pool of prokaryotes.

\section{INTRACLONAL GENOME DIVERSITY}

The comparison of published genome sequences of clonally unrelated strains uncovered an interclonal sequence diversity of the $P$. aeruginosa core genome of $0.5-0.7 \%$ (Spencer et al., 2003; Cramer et al., 2011). The intraclonal diversity of members of the same clonal complex, however, is yet unknown. Of the strains with completely sequenced genomes, only strain PA14 belongs to a common clonal complex in the $P$. aeruginosa population (Wiehlmann et al., 2007). Hence we decided to sequence another strain of the PA14 clonal complex by Illumina sequencing-bysynthesis technology [study accession number ERP000390 at the Nucleotide Read Archive (ENA) of the EBI]. This strain RN3 was

${ }^{2}$ http://www.pseudomonas.com/geneSearch.jsp

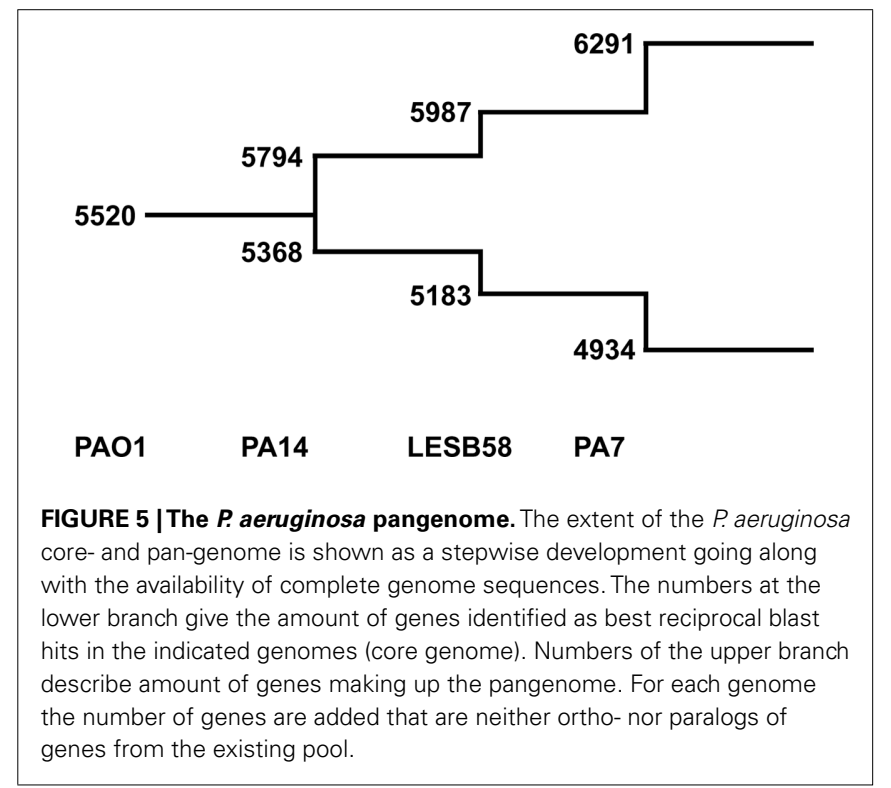

isolated from the first $P$. aeruginosa-positive airway specimen of an individual with cystic fibrosis who was living in North-West Germany. Strain PA14 is a clinical isolate from California. Thus the two strains are of unrelated geographic origin.

The strain PA14 and strain RN3 genomes match in genome size and differ in 231 SNPs from each other (Table 4) which corresponds to a sequence diversity of $3.5 \times 10^{-5}$. Transitions $(n=148)$ occurred significantly more frequently than the expected ratio of transitions to transversions of 55: 176 of a random distribution $\left(\chi^{2}=206.3 ; P<0.001\right)$. The number of SNPs in inter- and intragenic regions roughly corresponded with their proportions in the genome. Within the coding regions synonymous SNPs were significantly overrepresented $\left(\chi^{2}=23.2 ; P<0.001\right)$ indicating that de novo amino acid substitutions had been subject to purifying selection.

Of the 231 SNPs, only 33 SNPs followed the statistics of a random distribution in the genome (Figure 6). In other words, 198 SNPs were non-randomly distributed in the genome implying that the affected loci had been subject to diversifying selection.

The major hotspot is the phage Pf1-like gene cluster (PA14_48890-PA14_49000) with 87 SNPs, i.e., 38\% of all SNPs. Thus phage Pf1 seems to be the most rapidly evolving part of the PA14 genome consistent with the view that phages span a high degree of genetic diversity and are prone to frequent horizontal transfer (Hatfull, 2008).

Non-synonymous SNPs were mainly found in the functional categories of transcriptional regulators, membranes, cellular appendages, transport, and secretion (Table 4). Hotspots of sequence diversity in single genes between the PA14 and RN3 genomes are $f t s Z, \operatorname{armB}(\operatorname{mexH})$, and $c y n S$ with six, five, and four SNPs, respectively. FtsZ is the major tubulin-like cytoskeletal protein in the bacterial cytokinesis machine (Erickson et al., 2010) and hence we noted with surprise that the Fts $Z$ proteins of strains PA14 and RN3 differ at five positions in their amino acid sequence. The substitutions P-L, M-L, G-D, T-N, and P-T are located within a stretch of 35 amino acids of the 394 aa 
Table 4 | Single nucleotide substitutions in RN3 sequence (compared to PA14 reference).

\begin{tabular}{|c|c|c|c|c|c|}
\hline Intragenic position & nt & Locus_tag & aa & Gene name & Encoded product \\
\hline 72440 & $T-C$ & PA14_00740 & $K-E$ & & Putative lipoprotein \\
\hline 96307 & $A-C$ & PA14_00970 & syn. & & Hypothetical protein \\
\hline 477483 & $G-A$ & PA14_05410 & syn. & $\operatorname{chpC}$ & putative chemotaxis protein \\
\hline 480880 & $T-C$ & PA14_05450 & syn. & & $16 \mathrm{~S}$ ribosomal RNA methyltransferase RsmE \\
\hline 741080 & $G-A$ & PA14_08660 & & & tRNA ${ }^{\text {Gly }}$ \\
\hline 747764 & $G-A$ & PA14_08760 & $G-D$ & $r p o B$ & DNA-directed RNA polymerase subunit beta \\
\hline 791890 & $A-G$ & PA14_09280 & $N-D$ & pchF & Pyochelin synthetase \\
\hline $888038^{2}$ & $C-T$ & PA14_10290 & $P-L$ & $\operatorname{acoR}$ & Transcriptional regulator AcoR \\
\hline $888039^{2}$ & $T-G$ & PA14_10290 & $P-L$ & $\operatorname{aco} R$ & Transcriptional regulator AcoR \\
\hline 1356548 & $G-C$ & PA14_15920 & $R-G$ & yhjE & Major facilitator transporter \\
\hline 1441164 & $T-C$ & PA14_16820 & syn. & & Putative efflux transmembrane protein \\
\hline 1468998 & $\mathrm{C}-\mathrm{T}$ & PA14_17130 & syn. & $d x r$ & 1-deoxy-d-xylulose 5-phosphate reductoisomerase \\
\hline 1551564 & $G-A$ & PA14_18080 & $A-V$ & & TetR family transcriptional regulator \\
\hline 1558205 & $A-G$ & PA14_18150 & syn. & acsL & Putative acetyl-CoA synthetase \\
\hline 1612742 & $A-G$ & PA14_18740 & syn. & $\arg G$ & Argininosuccinate synthase \\
\hline 1640196 & $\mathrm{G}-\mathrm{T}$ & PA14_18985 & $\mathrm{P}-\mathrm{H}$ & & Hypothetical protein \\
\hline 1640394 & $A-G$ & PA14_18985 & $F-S$ & & Hypothetical protein \\
\hline 1880872 & $C-G$ & PA14_21690 & $A-G$ & Ihr1 & Putative ATP-dependent DNA helicase \\
\hline 1960256 & $C-A$ & PA14_22520 & $R-L$ & & Hypothetical protein \\
\hline 2510099 & $A-G$ & PA14_29030 & $T-A$ & & Putative FMN oxidoreductase \\
\hline 2545609 & $T-C$ & PA14_29390 & syn. & & Hypothetical protein \\
\hline 2545663 & $T-C$ & PA14_29390 & syn. & & Hypothetical protein \\
\hline 2553747 & $\mathrm{~T}-\mathrm{C}$ & PA14_29440 & $D-G$ & & LysR family transcriptional regulator \\
\hline 2651339 & $T-C$ & PA14_30600 & $F-L$ & & Putative permease \\
\hline 2651357 & $A-G$ & PA14_30600 & $N-D$ & & Putative permease \\
\hline 2762006 & $A-G$ & PA14_31750 & $K-E$ & & Putative acyltransferase \\
\hline 2787777 & $C-G$ & PA14_32015³ & & $C z C A$ & Homolog to RND efflux transporter CzcA \\
\hline 2787784 & $T-G$ & PA14_32015³ & & $c z c A$ & Homolog to RND efflux transporter CzcA \\
\hline 2807266 & $\mathrm{G}-\mathrm{C}$ & PA14_32300 & $V-L$ & & Putative kinase \\
\hline 2885933 & $G-C$ & PA14_32985 & syn. & gcvH2 & Glycine cleavage system protein $\mathrm{H}$ \\
\hline 2955357 & $A-G$ & PA14_33600 & syn. & & Hypothetical protein \\
\hline 2955433 & $A-G$ & PA14_33600 & syn. & & Hypothetical protein \\
\hline 2955468 & $A-G$ & PA14_33600 & syn. & & Hypothetical protein \\
\hline 2985345 & $A-G$ & PA14_33650 & $K-E$ & $p v d D$ & Pyoverdine synthetase $D$ \\
\hline 3198441 & $T-G$ & PA14_35940 & syn. & & Acyl-CoA synthetase \\
\hline 3373667 & $G-C$ & PA14_37830 & syn. & iscs & Putative pyridoxal-phosphate dependent enzyme \\
\hline 3374601 & $A-G$ & PA14_37830 & $F-S$ & iscS & Putative pyridoxal-phosphate dependent enzyme \\
\hline
\end{tabular}

(Continued) 
Table 4 | Continued

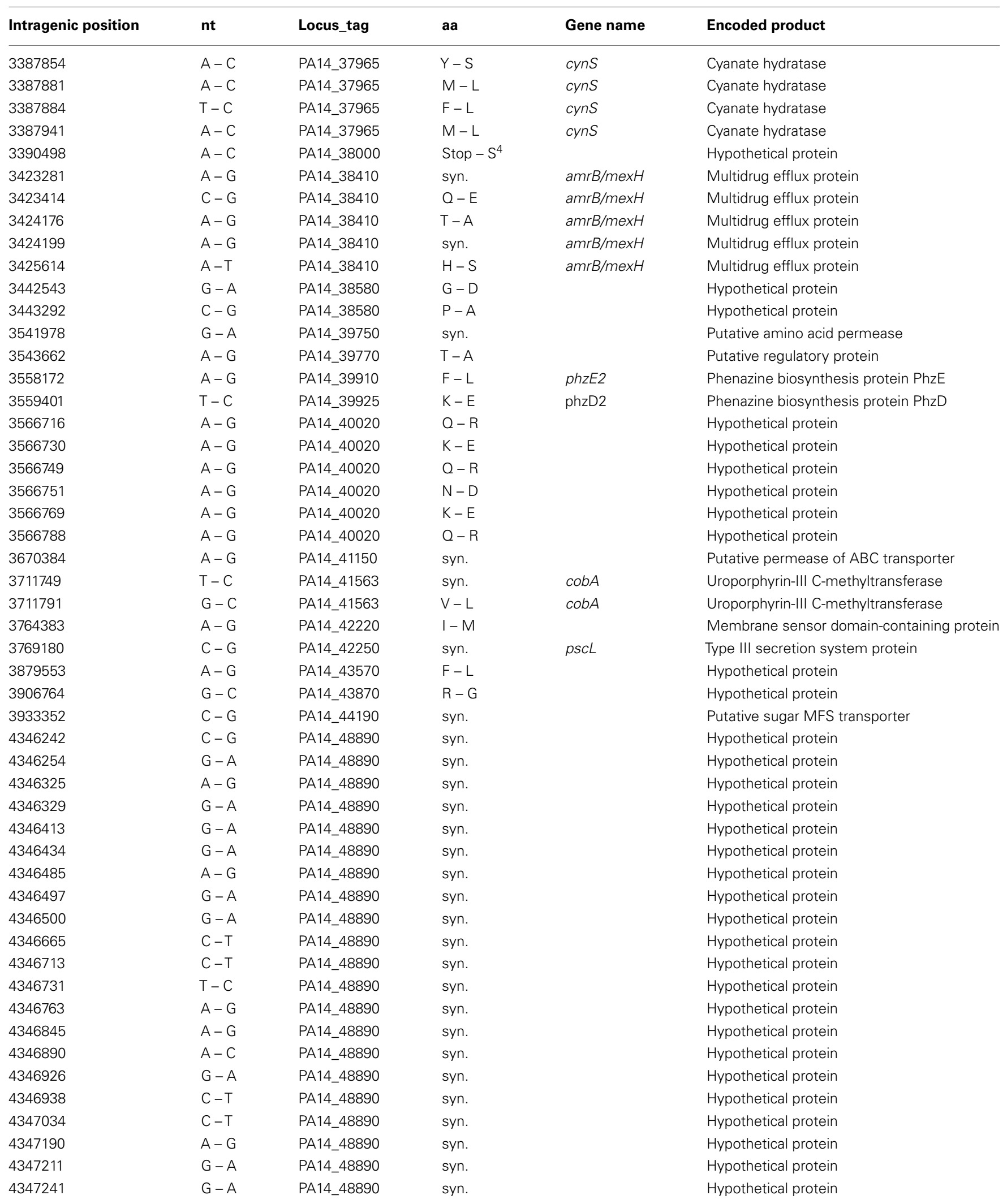


Table 4 | Continued

\begin{tabular}{|c|c|c|c|c|c|}
\hline Intragenic position & nt & Locus_tag & aa & Gene name & Encoded product \\
\hline 4347256 & $C-T$ & PA14_48890 & syn. & & Hypothetical protein \\
\hline 4347283 & $T-C$ & PA14_48890 & syn. & & Hypothetical protein \\
\hline 4347310 & $T-C$ & PA14_48890 & syn. & & Hypothetical protein \\
\hline 4347322 & $T-C$ & PA14_48890 & syn. & & Hypothetical protein \\
\hline 4347376 & $C-G$ & PA14_48890 & syn. & & Hypothetical protein \\
\hline 4347642 & $G-A$ & PA14_48900 & $A-V$ & & Hypothetical protein \\
\hline 4347673 & $\mathrm{~T}-\mathrm{A}$ & PA14_48900 & $T-S$ & & Hypothetical protein \\
\hline 4347701 & $C-A$ & PA14_48900 & syn. & & Hypothetical protein \\
\hline 4347825 & $G-T$ & PA14_48910 & $P-T$ & & Hypothetical protein \\
\hline 4348308 & $G-A$ & PA14_48910 & syn. & & Hypothetical protein \\
\hline 4348378 & $G-T$ & PA14_48910 & syn. & & Hypothetical protein \\
\hline 4348501 & $A-G$ & PA14_48910 & syn. & & Hypothetical protein \\
\hline 4348684 & $A-G$ & PA14_48910 & syn. & & Hypothetical protein \\
\hline 4348966 & $T-G$ & PA14_48910 & syn. & & Hypothetical protein \\
\hline 4349128 & $A-C$ & PA14_48920 & syn. & & Bacteriophage protein \\
\hline 4350200 & $A-T$ & PA14_48930 & syn. & & Putative coat protein A of bacteriophage Pf1 \\
\hline 4350213 & $G-C$ & PA14_48930 & $A-G$ & & Putative coat protein A of bacteriophage Pf1 \\
\hline 4350484 & $T-C$ & PA14_48930 & $N-D$ & & Putative coat protein A of bacteriophage Pf1 \\
\hline 4350502 & $T-C$ & PA14_48930 & $T-A$ & & Putative coat protein A of bacteriophage Pf1 \\
\hline 4351199 & $\mathrm{G}-\mathrm{A}$ & PA14_48950 & syn. & & Hypothetical protein \\
\hline 4351316 & $A-G$ & PA14_48950 & syn. & & Hypothetical protein \\
\hline 4351503 & $\mathrm{G}-\mathrm{A}$ & PA14_48970 & syn. & & Helix destabilizing protein of bacteriophage Pf1 \\
\hline 4351563 & $T-C$ & PA14_48970 & syn. & & Helix destabilizing protein of bacteriophage Pf1 \\
\hline 4351617 & $A-G$ & PA14_48970 & syn. & & Helix destabilizing protein of bacteriophage Pf1 \\
\hline 4351641 & $C-G$ & PA14_48970 & syn. & & Helix destabilizing protein of bacteriophage Pf1 \\
\hline 4351722 & $A-G$ & PA14_48970 & syn. & & Helix destabilizing protein of bacteriophage Pf1 \\
\hline 4351857 & $G-A$ & PA14_48970 & syn. & & Helix destabilizing protein of bacteriophage Pf1 \\
\hline 4352075 & $A-G$ & PA14_48980 & syn. & & Hypothetical protein \\
\hline 4352106 & $\mathrm{~T}-\mathrm{C}$ & PA14_48980 & $D-G$ & & Hypothetical protein \\
\hline 4352113 & $C-A$ & PA14_48980 & $D-Y$ & & Hypothetical protein \\
\hline 4352144 & $\mathrm{G}-\mathrm{C}$ & PA14_48980 & $S-R$ & & Hypothetical protein \\
\hline 4352234 & $G-A$ & PA14_48980 & syn. & & Hypothetical protein \\
\hline 4352294 & $\mathrm{G}-\mathrm{C}$ & PA14_48980 & syn. & & Hypothetical protein \\
\hline 4352384 & $\mathrm{C}-\mathrm{T}$ & PA14_48980 & syn. & & Hypothetical protein \\
\hline 4352465 & $G-T$ & PA14_48990 & syn. & & Hypothetical protein \\
\hline 4352471 & $G-A$ & PA14_48990 & syn. & & Hypothetical protein \\
\hline 4352545 & $C-A$ & PA14_48990 & $A-S$ & & Hypothetical protein \\
\hline
\end{tabular}


Table 4 | Continued

\begin{tabular}{|c|c|c|c|c|c|}
\hline Intragenic position & nt & Locus_tag & aa & Gene name & Encoded product \\
\hline 4352560 & $G-A$ & PA14_48990 & $P-S$ & & Hypothetical protein \\
\hline 4352594 & $C-G$ & PA14_48990 & syn. & & Hypothetical protein \\
\hline 4352676 & $G-C$ & PA14_48990 & $A-G$ & & Hypothetical protein \\
\hline 4352700 & $T-C$ & PA14_48990 & $H-R$ & & Hypothetical protein \\
\hline $4352866^{2}$ & $\mathrm{~T}-\mathrm{C}$ & PA14_49000 & $I-G$ & & Hypothetical protein \\
\hline 4352921 & $C-A$ & PA14_49000 & $M-1$ & & Hypothetical protein \\
\hline 4450619 & $T-G$ & PA14_50060 & $L-R$ & & Hypothetical protein \\
\hline 4565005 & $C-G$ & PA14_51360 & $G-A$ & phnA & Hnthranilate synthase component I \\
\hline 4565040 & $A-G$ & PA14_51360 & syn. & phnA & Hnthranilate synthase component I \\
\hline 4901696 & $A-G$ & PA14_55180 & $M-V$ & $\operatorname{mig} A$ & Glycosyl transferase \\
\hline 4912690 & $C-T$ & PA14_55330 & $\mathrm{D}-\mathrm{N}$ & & Hypothetical protein \\
\hline 4947683 & $A-G$ & PA14_55600 & $H-R$ & & Hypothetical protein \\
\hline 4997786 & $T-C$ & PA14_55980 & $K-E$ & $y j g R$ & Hypothetical protein \\
\hline 5041775 & $A-T$ & PA14_56550 & syn. & & Hypothetical protein \\
\hline $5103224^{2}$ & $A-C$ & PA14_57275 & $P-L$ & $f t s Z$ & Cell division protein FtsZ \\
\hline $5103225^{2}$ & $G-A$ & PA14_57275 & $P-L$ & $f t s Z$ & Cell division protein FtsZ \\
\hline 5103259 & $T-G$ & PA14_57275 & $M-L$ & $\mathrm{fts} Z$ & Cell division protein FtsZ \\
\hline 5103291 & $C-T$ & PA14_57275 & $G-D$ & $f t s Z$ & Cell division protein FtsZ \\
\hline 5103303 & $G-T$ & PA14_57275 & $\mathrm{T}-\mathrm{N}$ & $f t s Z$ & Cell division protein FtsZ \\
\hline 5757527 & $G-C$ & PA14_64620 & $P-R$ & & Putative oxidoreductase \\
\hline 5809365 & $T-C$ & PA14_65190 & $K-E$ & yjfH & TrmH family RNA methyltransferase, group 3 \\
\hline 5866730 & $T-G$ & PA14_65860 & syn. & & Putative two-component sensor \\
\hline 5905079 & $A-G$ & PA14_66270 & syn. & $g \ln E$ & Glutamine-synthetase adenylyltransferase \\
\hline 5968025 & $C-G$ & PA14_66820 & $P-A$ & phaC1 & Poly(3-hydroxyalkanoic acid) synthase 1 \\
\hline 6070122 & $T-C$ & PA14_6802033 & & & Homolog to hypothetical protein PA5149 \\
\hline 6076066 & $G-C$ & PA14_68100 & syn. & & Hypothetical protein \\
\hline 6412470 & $G-C$ & PA14_71930 & $R-G$ & $w b p X$ & Glycosyltransferase WbpX \\
\hline 6441338 & $\mathrm{~T}-\mathrm{C}$ & PA14_72300 & $L-P$ & & Hypothetical protein \\
\hline Intergenic position & nt & Intergenic region & & & \\
\hline 151966 & $A-G$ & igrPA14_01660-01670 & & & \\
\hline 187759 & $G-T$ & igrPA14_02050-02060 & & & \\
\hline 208430 & $T-G$ & igrPA14_02310-02330 & & & \\
\hline 208433 & $G-C$ & igrPA14_02310-02330 & & & \\
\hline 888497 & $A-C$ & igrPA14_10290-10300 & & & \\
\hline 966217 & $T-C$ & igrPA14_11110-11120 & & & \\
\hline 1144646 & $C-G$ & igrPA14_13320-13330 & & & \\
\hline
\end{tabular}


Table 4 | Continued

\begin{tabular}{|c|c|c|}
\hline Intergenic position & nt & Intergenic region \\
\hline 1375947 & $A-G$ & igrPA14_16150-16160 \\
\hline 1725505 & $A-G$ & igrPA14_20020-20030 \\
\hline 1923008 & $C-T$ & igrPA14_22080-22090 \\
\hline 2354149 & $A-G$ & igrPA14_27090-27100 \\
\hline 2589402 & $C-T$ & igrPA14_29890-29900 \\
\hline 2840442 & $\mathrm{~T}-\mathrm{C}$ & igrPA14_32700-32710 \\
\hline 2840444 & $T-C$ & igrPA14_32700-32710 \\
\hline 3281477 & $G-C$ & igrPA14_36810-36820 \\
\hline 3356495 & $G-C$ & igrPA14_37680-37690 \\
\hline 4352019 & $\mathrm{~T}-\mathrm{G}$ & igrPA14_48970-48980 \\
\hline 4352023 & $C-G$ & igrPA14_48970-48980 \\
\hline 4352432 & $G-A$ & igrPA14_48980-48990 \\
\hline 4352433 & $G-A$ & igrPA14_48980-48990 \\
\hline 4407236 & $A-G$ & igrPA14_49540-49560 \\
\hline 4659805 & $A-G$ & igrPA14_52530-52540 \\
\hline 4708161 & $A-G$ & igrPA14_53110-53120 \\
\hline 5198405 & $T-C$ & igrPA14_58360-58375 \\
\hline 5200474 & $A-C$ & igrPA14_58380-58390 \\
\hline 5565118 & $A-G$ & igrPA14_62380-62390 \\
\hline
\end{tabular}

${ }^{1}$ Protein length 180 aa instead of 264.

${ }^{2}$ Two SNPs in one codon.

${ }^{3}$ Annotated as probably inactive protein fragment/putative frameshift gene.

${ }^{4}$ Next stop 18 codons downstream.

protein and are all not neutral (Table 4). MexH is a component of the MexGHI-OpmD efflux pump that is required for biofilm formation (Southey-Pillig et al., 2005), facilitates cell-to-cell communication and promotes virulence and growth in $P$. aeruginosa (Aendekerk et al., 2005). MexH of strains PA14 and RN3 differ by three amino acid substitutions (Q-E, T-A, and H-S) in three distant domains of the protein from each other. CynS encodes a cyanase (EC 4.2.1.104) that catalyzes the decomposition of cyanate into $\mathrm{CO}_{2}$ and ammonium (Luque-Almagro et al., 2008). The intraclonal diversity of cyanase between RN3 and PA14 of four amino acid substitutions is similar in number and localization to that of the completely sequenced $P$. aeruginosa strains, i.e., 5-11 amino acid substitutions clustering in the N-terminal region of CynS.

Key genes were also affected by non-synonymous SNPs that may modulate the function of the gene products. The DNAdirected RNA polymerase RpoB of strain RN3 carries a substitution of a glycine by an aspartate, and the global regulator RetS of the sessile and planktonic lifestyle of P. aeruginosa, which is involved in the transition from acute to chronic infections (Goodman et al., 2004), harbors a substitution of an aspartate by an alanine.

Of the 34 observed amino acid substitution types, nine are classified by the Dayhoff (1978) matrix as uncommon and associated with an impact on protein function. In contrast, only 12 of the 20 most common neutral amino acid changes were seen. In summary, SNPs non-randomly targeted elements of the cell surface and uncommon non-neutral substitutions (e.g., K-E) were overrepresented in the affected proteins. These facts suggest that in the investigated case the intraclonal diversity did not evolve by random drift, but was driven by selective forces.

Strain RN3 was isolated from the first $P$. aeruginosapositive specimen taken from an individual with cystic fibrosis. Thus the portion of adaptive mutations that typically emerge during chronic colonization of cystic fibrosis airways (Smith et al., 2006) should be low. Nevertheless some sequence differences between RN3 and PA14 could provide RN3 with 


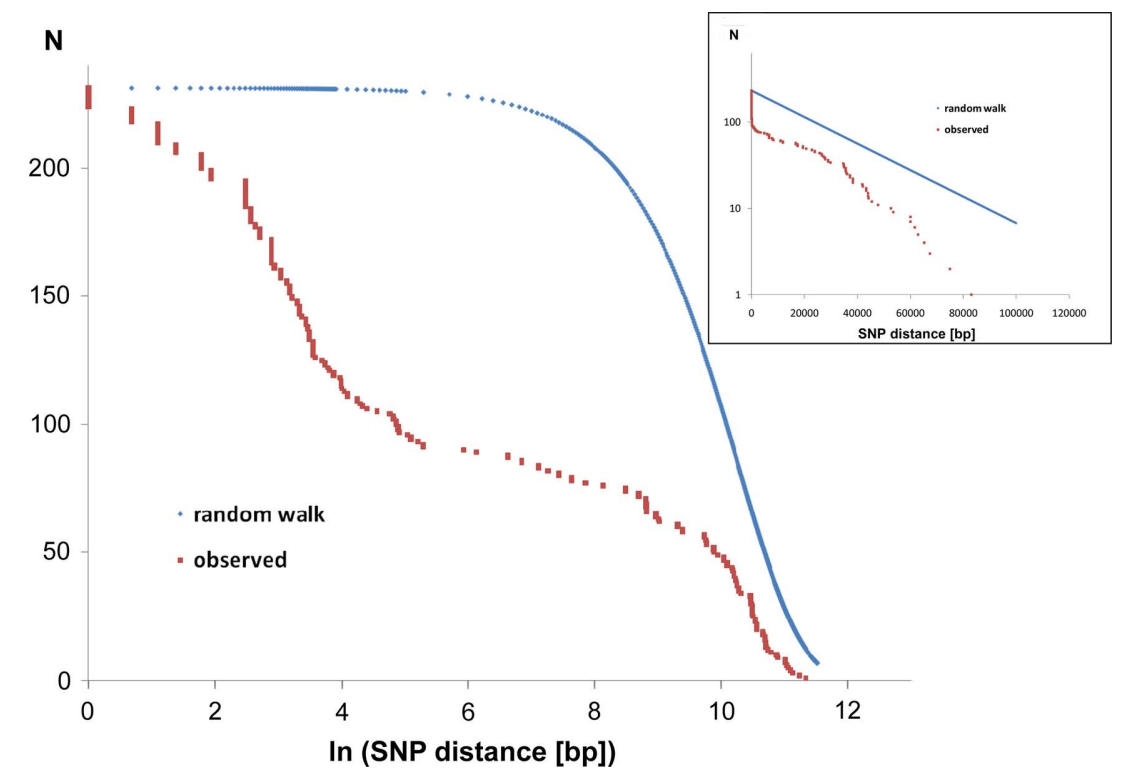

FIGURE 6 | Intraclonal SNP diversity of the $P$. aeruginosa PA14 clone: distribution of nearest SNP neighbors in the RN3 genome. Mapping of the RN3 genome onto the PA14 genome uncovered 231 SNPs. The figure depicts the genomic distribution of the distance between two adjacent SNPs (nearest neighbors). The red graphs show the observed distribution that is compared with a random genomic distribution of the same number of 231 SNPs (blue graphs, one-dimensional random walk statistics). The two semilogarithmic plots visualize the deviation from a random distribution at either a global scale (insert) or with focus on the hotspots of sequence diversity (large figure). selective advantage to adapt and persist in cystic fibrosis airways. Obvious candidates are loci encoding efflux pumps (mexH), major transcriptional regulators (retS), and siderophore $(p v d D)$, cyanide $(c y n S)$, or quinolone (phnA) biosynthesis, respectively.

The major take home message of our endeavor to compare the intraclonal genome diversity of strains of distant geographic origin was the unexpectedly low substitution rate. Statistical analysis provides strong evidence that nucleotide substitutions in coding regions were under purifying selection so that only a low number of substitutions was fixed. This versatile, ubiquitous and phylogenetically ancient organism apparently does not need many de novo mutations if it conquers a new habitat. The next step to understand the molecular evolution of intraclonal diversity would be the determination of the relative contributions of de novo mutation versus recombination. To accomplish this task, a larger collection of clone PA14 strains than just two isolates will have to be studied (see Spratt, 2004, for an appropriate study design).

\section{REFERENCES}

Aendekerk, S., Diggle, S. P., Song, Z., Høiby, N., Cornelis, P., Williams, P., and Cámara, M. (2005). The MexGHI-OpmD multidrug efflux pump controls growth, antibiotic susceptibility and virulence in Pseudomonas aeruginosa via 4-quinolone-dependent cell-to-cell communication. Microbiology 151(Pt 4), 1113-1125.
Arora, S. K., Wolfgang, M. C., Lory, S., and Ramphal, R. (2004). Sequence polymorphism in the glycosylation island and flagellins of Pseudomonas aeruginosa. J. Bacteriol. 186, 2115-2122.

Battle, S. E., Meyer, F., Rello, J., Kung, V. L., and Hauser, A. R. (2008). Hybrid pathogenicity island PAGI-5 contributes to the highly virulent phenotype of a Pseudomonas aeruginosa

\section{PERSPECTIVES}

Only four completely sequenced $P$. aeruginosa genomes are officially deposited as finished genomes in GenBank. Draft genomes exist for a five further genomes and several dozen $P$. aeruginosa projects are deposited in the ENA hosted by EMBL-EBI (see text footnote 1). Many of the projects were done for the purpose of (re)sequencing variants of already known strains. Thorough genome assemblies and functional annotations are probably intended only in a minority of cases. But nevertheless an immense increase in $P$. aeruginosa genome data is expected to become available in the near future due to the on-going revolution of sequencing technologies. In particular, the sequencing of strains from environmental habitats should provide us with an unbiased overview of the genetic repertoire of the P. aeruginosa population.

\section{ACKNOWLEDGMENT}

This work was supported by the Deutsche Forschungsgemeinschaft (SFB 900: Chronic Infections: Microbial Persistence and its Control; project A2).

isolate in mammals. J. Bacteriol. 190 7130-7140.

Battle, S. E., Rello, J., and Hauser, A. R. (2009). Genomic islands of Pseudomonas aeruginosa. FEMS Microbiol. Lett. 290, 70-78.

Carter, M. Q., Chen, J., and Lory, S. (2010). The Pseudomonasaeruginosa pathogenicity island PAPI-1 is transferred via a novel type IV pilus. $J$. Bacteriol. 192, 3249-3258.
Cheng, K., Smyth, R. L., Govan, J. R., Doherty, C., Winstanley, C., Denning, N., Heaf, D. P., van Saene, H., and Hart, C. A. (1996). Spread of beta-lactam-resistant Pseudomonas aeruginosa in a cystic fibrosis clinic. Lancet 348, 639-642.

Cramer, N., Klockgether, J., Wrasman, K., Schmidt, M., Davenport, C., and Tümmler, B. (2011). Microevolution of the major common 
Pseudomonas aeruginosa clones C and PA14 in cystic fibrosis lungs. Environ. Microbiol. 13, 1590-1604.

Davenport, C. F., Wiehlmann, L., Reva, O. N., and Tümmler, B. (2009). Visualization of Pseudomonas genomic structure by abundant 8 -14mer oligonucleotides. Environ. Microbiol. 11, 1092-1104.

Dayhoff, M. O. (1978). Atlas of Protein Sequence and Structure, Observed Frequencies of Amino Acid Replacements Between Closely Related Proteins, Vol. 5, Suppl. 3. Washington, DC: National Biomedical Research foundation.

Dobrindt, U., Hochhut, B., Hentschel, U., and Hacker, J. (2004). Genomic islands in pathogenic and environmental microorganisms. Nat. Rev. Microbiol. 2, 414-424.

Dötsch, A., Klawonn, F., Jarek, M., Scharfe, M., Blöcker, H., and Häussler, S. (2010). Evolutionary conservation of essential and highly expressed genes in Pseudomonas aeruginosa. BMC Genomics 11, 234. doi: 10.1186/1471-2164-11-234

Erickson, H. P., Anderson, D. E., and Osawa, M. (2010). FtsZ in bacterial cytokinesis: cytoskeleton and force generator all in one. Microbiol. Mol. Biol. Rev. 74, 504-528.

Ernst, R. K., D'Argenio, D. A., Ichikawa, J. K., Bangera, M. G., Selgrade, S., Burns, J. L., Hiatt, P., McCoy, K., Brittnacher, M., Kas, A., Spencer, D. H., Olson, M. V., Ramsey, B. W., Lory, S., and Miller, S. I. (2003). Genome mosaicism is conserved but not unique in Pseudomonas aeruginosa isolates from the airways of young children with cystic fibrosis. Environ. Microbiol. 5, 1341-1349.

Frank, S., Klockgether, J., Hagendorf, P., Geffers, R., Schöck, U., Pohl, T., Davenport, C. F., and Tümmler, B. (2011). Pseudomonas putida KT2440 genome update by cDNA sequencing and microarray transcriptomics. Environ. Microbiol. 13, 1309-1326.

Gaillard, M., Pernet, N., Vogne, C., Hagenbüchle, O., and van der Meer, J. R. (2008). Host and invader impact of transfer of the clc genomic island into Pseudomonas aeruginosa PAO1. Proc. Natl. Acad. Sci. U.S.A. 105, 7058-7063.

Giltner, C. L., Rana, N., Lunardo, M. N., Hussain, A. Q., and Burrows, L. L. (2011). Evolutionary and functional diversity of the Pseudomonas type IVa pilin island. Environ. Microbiol. 13, 250-264.

Goodman, A. L., Kulasekara, B., Rietsch, A., Boyd, D., Smith, R. S., and Lory, S. (2004). A signaling network reciprocally regulates genes associated with acute infection and chronic persistence in Pseudomonas aeruginosa. Dev. Cell 7, 745-754.

Hatfull, G. F. (2008). Bacteriophage genomics. Curr. Opin. Microbiol. 11, 447-453.

He, J., Baldini, R. L., Déziel, E., Saucier, M., Zhang, Q., Liberati, N. T., Lee, D., Urbach, J., Goodman, H. M., and Rahme, L. G. (2004). The broad host range pathogen Pseudomonas aeruginosa strain PA14 carries two pathogenicity islands harboring plant and animal virulence genes. Proc. Natl. Acad. Sci. U.S.A. 101, 2530-2535.

Kiewitz, C., Larbig, K., Klockgether, J., Weinel, C., and Tümmler, B. (2000). Monitoring genome evolution ex vivo: reversible chromosomal integration of a $106 \mathrm{~kb}$ plasmid at two tRNA(Lys) gene loci in sequential Pseudomonas aeruginosa airway isolates. Microbiology $146(\mathrm{Pt}$ 10), 2365-2373.

Klockgether, J., Munder, A., Neugebauer, J., Davenport, C. F., Stanke, F., Larbig, K. D., Heeb, S., Schöck, U., Pohl, T. M., Wiehlmann, L., and Tümmler, B. (2010). Genome diversity of Pseudomonas aeruginosa PAO1 laboratory strains. J. Bacteriol. 192, 1113-1121.

Klockgether, J., Reva, O., Larbig, K., and Tümmler, B. (2004). Sequence analysis of the mobile genome island pKLC102 of Pseudomonas aeruginosa C. J. Bacteriol. 186, 518-534.

Klockgether, J., Würdemann, D., Reva, O., Wiehlmann, L., and Tümmler, B. (2007). Diversity of the abundant pKLC102/PAGI-2 family of genomic islands in Pseudomonas aeruginosa. J. Bacteriol. 189, 2443-2459.

Klockgether, J., Würdemann, D., Wiehlmann, L., Binnewies, T. T., Ussery, D. W., and Tümmler, B. (2008). "Genome diversity of Pseudomonas aeruginosa," in Pseudomonas Genomics and Molecular Biology, ed. P. Cornelis (Norfolk: Caister Academic Press), 19-42.

Kresse, A. U., Dinesh, S. D., Larbig, K., and Römling, U. (2003). Impact of large chromosomal inversions on the adaptation and evolution of Pseudomonas aeruginosa chronically colonizing cystic fibrosis lungs. Mol. Microbiol. 47, 145-158.

Kulasekara, B. R., Kulasekara, H. D., Wolfgang, M. C., Stevens, L., Frank, D. W., and Lory, S. (2006). Acquisition and evolution of the exoU locus in Pseudomonas aeruginosa. J. Bacteriol. 188, 4037-4050.

Kung, V. L., Ozer, E. A., and Hauser, A. R. (2010). The accessory genome of Pseudomonas aeruginosa. Microbiol. Mol. Biol. Rev. 74, 621-641.
Kus, J. V., Tullis, E., Cvitkovitch, D. G. and Burrows, L. L. (2004). Significant differences in type IV pilin allele distribution among Pseudomonas aeruginosa isolates from cystic fibrosis (CF) versus non-CF patients. Microbiology 150(Pt 5), 1315-1326.

Larbig, K. D., Christmann, A., Johann, A., Klockgether, J., Hartsch, T., Merkl, R., Wiehlmann, L., Fritz, H. J., and Tümmler, B. (2002). Gene islands integrated into tRNA(Gly) genes confer genome diversity on a Pseudomonas aeruginosa clone. $J$. Bacteriol. 184, 6665-6680.

Lee, D. G., Urbach, J. M., Wu, G., Liberati, N. T., Feinbaum, R. L., Miyata, S., Diggins, L. T., He, J., Saucier, M., Déziel, E., Friedman, L., Li, L., Grills, G., Montgomery, K., Kucherlapati, R., Rahme, L. G. and Ausubel, F. M. (2006). Genomic analysis reveals that Pseudomonas aeruginosa virulence is combinatorial. Genome Biol. 7, R90.

Liang, X., Pham, X. Q., Olson, M. V., and Lory, S. (2001). Identification of a genomic island present in the majority of pathogenic isolates of Pseudomonas aeruginosa. J. Bacteriol. 183, 843-853.

Luque-Almagro, V. M., Huertas, M. J., Sáez, L. P., Luque-Romero, M. M., Moreno-Vivián, C., Castillo, F., Roldán, M. D., and Blasco, R. (2008). Characterization of the Pseudomonas pseudoalcaligenes CECT5344 cyanase, an enzyme that is not essential for cyanide assimilation. Appl. Environ. Microbiol. 74 6280-6288.

Mathee, K., Narasimhan, G., Valdes, C. Qiu, X., Matewish, J. M., Koehrsen, M., Rokas, A., Yandava, C. N., Engels, R., Zeng, E., Olavarietta, R., Doud, M., Smith, R. S., Montgomery, P., White, J. R., Godfrey, P. A., Kodira, C., Birren, B., Galagan, J. E., and Lory, S. (2008). Dynamics of Pseudomonas aeruginosa genome evolution. Proc. Natl. Acad. Sci. U.S.A. 105, 3100-3105.

McCallum, S. J., Gallagher, M. J., Corkill, J. E., Hart, C. A., Ledson, M. J. and Walshaw, M. J. (2002). Spread of an epidemic Pseudomonas aeruginosa strain from a patient with cystic fibrosis (CF) to non-CF relatives. Thorax 57, 559-560.

Mohd-Zain, Z., Turner, S. L., CerdeñoTárraga, A. M., Lilley, A. K., Inzana, T. J., Duncan, A. J., Harding, R. M., Hood, D. W., Peto, T. E., and Crook, D. W. (2004). Transferable antibiotic resistance elements in Haemophilus influenzae share a common evolutionary origin with a diverse family of syntenic genomic islands. $J$. Bacteriol. 186, 8114-8122.
Moya, B., Dötsch, A., Juan, C., Blázquez, J., Zamorano, L., Häussler, S., and Oliver, A. (2009). Beta-lactam resistance response triggered by inactivation of a nonessential penicillin-binding protein. PLoS Pathog. 5, e1000353. doi: 10.1371/journal.ppat.1000353

Qiu, X., Gurkar, A. U., and Lory, S. (2006). Interstrain transfer of the large pathogenicity island (PAPI1) of Pseudomonas aeruginosa. Proc. Natl. Acad. Sci. U.S.A. 103, 19830-19835.

Ramos, J. L. (ed.). (2004). Pseudomonas Volume 1: Genomics, Life Style and Molecular Architecture. New York: Kluwer Academics/Plenum Publishers.

Raymond, C. K., Sims, E. H., Kas, A., Spencer, D. H., Kutyavin, T. V., Ivey, R. G., Zhou, Y., Kaul, R., Clendenning, J. B., and Olson, M. V. (2002). Genetic variation at the O-antigen biosynthetic locus in Pseudomonas aeruginosa. J. Bacteriol. 184, 3614-3622.

Reva, O. N., and Tümmler, B. (2004). Global features of sequences of bacterial chromosomes, plasmids and phages revealed by analysis of oligonucleotide usage patterns. BMC Bioinformatics 5, 90. doi: 10.1186/1471-2105-5-90

Reva, O. N., and Tümmler, B. (2005) Differentiation of regions with atypical oligonucleotide composition in bacterial genomes. BMC Bioinformatics 6, 251. doi: 10.1186/14712105-6-251

Römling, U., Greipel, J., and Tümmler, B. (1995). Gradient of genomic diversity in the Pseudomonas aeruginosa chromosome. Mol. Microbiol. 17, 323-332.

Römling, U., Schmidt, K. D., and Tümmler, B. (1997). Large genome rearrangements discovered by the detailed analysis of 21 Pseudomonas aeruginosa clone $\mathrm{C}$ isolates found in environment and disease habitats. $J$. Mol. Biol. 271, 386-404.

Roy, P. H., Tetu, S. G., Larouche, A., Elbourne, L., Tremblay, S., Ren, Q., Dodson, R., Harkins, D., Shay, R., Watkins, K., Mahamoud, Y., and Paulsen, I. T. (2010). Complete genome sequence of the multiresistant taxonomic outlier Pseudomonas aeruginosa PA7. PLoS ONE 5, e8842. doi: 10.1371/journal.pone.0008842

Schmidt, K. D., Tümmler, B., and Römling, U. (1996). Comparative genome mapping of Pseudomonas aeruginosa $\mathrm{PAO}$ with $P$. aeruginosa $\mathrm{C}$, which belongs to a major clone in cystic fibrosis patients and aquatic habitats. J. Bacteriol. 178, 85-93. 
Sharma, C. M., Hoffmann, S., Darfeuille, F., Reignier, J., Findeiss, S., Sittka, A., Chabas, S., Reiche, K., Hackermüller, J., Reinhardt, R., Stadler, P. F., and Vogel, J. (2010). The primary transcriptome of the major human pathogen Helicobacter pylori. Nature 464, 250-255.

Silby, M. W., Winstanley, C., Godfrey, S. A., Levy, S. B., and Jackson, R. W. (2011). Pseudomonas genomes: diverse and adaptable. FEMS Microbiol. Rev. 35, 652-680.

Smith, E. E., Buckley, D. G., Wu, Z., Saenphimmachak, C., Hoffman, L. R., D’Argenio, D. A., Miller, S. I., Ramsey, B. W., Speert, D. P., Moskowitz, S. M., Burns, J. L., Kaul, R., and Olson, M. V. (2006). Genetic adaptation by Pseudomonas aeruginosa to the airways of cystic fibrosis patients. Proc. Natl. Acad. Sci. U.S.A. 103, 8487-8492.

Smith, E. E., Sims, E. H., Spencer, D. H., Kaul, R., and Olson, M. V. (2005). Evidence for diversifying selection at the pyoverdine locus of Pseudomonas aeruginosa. J. Bacteriol. 187, 2138-2147.

Southey-Pillig, C. J., Davies, D. G., and Sauer, K. (2005). Characterization of temporal protein production in Pseudomonas aeruginosa biofilms. J. Bacteriol. 187, 8114-8126.
Spangenberg, C., Heuer, T., Bürger, C., and Tümmler, B. (1996). Genetic diversity of flagellins of Pseudomonas aeruginosa. FEBS Lett. 396, 213-217.

Spencer, D. H., Kas, A., Smith, E. E., Raymond, C. K., Sims, E. H., Hastings, M., Burns, J. L., Kaul, R., and Olson, M. V. (2003). Wholegenome sequence variation among multiple isolates of Pseudomonas aeruginosa. J. Bacteriol. 185, 1316-1325.

Spratt, B. G. (2004). Exploring the concept of clonality in bacteria. Methods Mol. Biol. 266, 323-352.

Stewart, R. M., Wiehlmann, L., Ashelford, K. E., Preston, S. J., Frimmersdorf, E., Campbell, B. J., Neal, T. J., Hall, N., Tuft, S., Kaye, S. B., and Winstanley, C. (2011). Genetic characterization indicates that a specific subpopulation of Pseudomonas aeruginosa is associated with keratitis infections. J. Clin. Microbiol. 49, 993-1003.

Stover, C. K., Pham, X. Q., Erwin, A. L., Mizoguchi, S. D., Warrener, P., Hickey, M. J., Brinkman, F. S., Hufnagle, W. O., Kowalik, D. J., Lagrou, M., Garber, R. L., Goltry, L., Tolentino, E., Westbrock-Wadman, S., Yuan, Y., Brody, L. L., Coulter, S. N., Folger, K. R., Kas, A., Larbig, K., Lim, R., Smith, K., Spencer, D., Wong, G. K., Wu, Z., Paulsen,
I. T., Reizer, J., Saier, M. H., Hancock, R. E., Lory, S., and Olson, M. V. (2000). Complete genome sequence of Pseudomonas aeruginosa PAO1, an opportunistic pathogen. Nature 406, 959-964.

Verma, A., Schirm, M., Arora, S. K., Thibault, P., Logan, S. M., and Ramphal, R. (2006). Glycosylation of btype flagellin of Pseudomonas aeruginosa: structural and genetic basis. $J$. Bacteriol. 188, 4395-4403.

Wiehlmann, L., Wagner, G., Cramer, N., Siebert, B., Gudowius, P., Morales, G., Köhler, T., van Delden, C., Weinel, C., Slickers, P., and Tümmler, B. (2007). Population structure of Pseudomonas aeruginosa. Proc. Natl. Acad. Sci. U.S.A. 104, 8101-8106.

Winsor, G. L., Van Rossum, T., Lo, R., Khaira, B., Whiteside, M. D., Hancock, R. E., and Brinkman, F. S. (2009). Pseudomonas Genome Database: facilitating user-friendly, comprehensive comparisons of microbial genomes. Nucleic Acids Res. 37, D483-D488.

Winstanley, C., Langille, M. G., Fothergill, J. L., Kukavica-Ibrulj, I., Paradis-Bleau, C., Sanschagrin, F., Thomson, N. R., Winsor, G. L., Quail, M. A., Lennard, N., Bignell, A., Clarke, L., Seeger, K., Saunders, D., Harris, D., Parkhill, J., Hancock, R. E., Brinkman, F. S., and Levesque,
R. C. (2009). Newly introduced genomic prophage islands are critical determinants of in vivo competitiveness in the Liverpool epidemic strain of Pseudomonas aeruginosa. Genome Res. 19, 12-23.

Conflict of Interest Statement: The authors declare that the research was conducted in the absence of any commercial or financial relationships that could be construed as a potential conflict of interest.

Received: 21 March 2011; paper pending published: 29 April 2011; accepted: 27 June 2011; published online: 13 July 2011. Citation: Klockgether J, Cramer N, Wiehlmann L, Davenport CF and Tümmler B (2011) Pseudomonas aeruginosa genomic structure and diversity. Front. Microbio. 2:150. doi: 10.3389/fmicb.2011.00150

This article was submitted to Frontiers in Cellular and Infection Microbiology, a specialty of Frontiers in Microbiology. Copyright (c) 2011 Klockgether, Cramer, Wiehlmann, Davenport and Tümmler. This is an open-access article subject to a non-exclusive license between the authors and Frontiers Media SA, which permits use, distribution and reproduction in other forums, provided the original authors and source are credited and other Frontiers conditions are complied with. 